

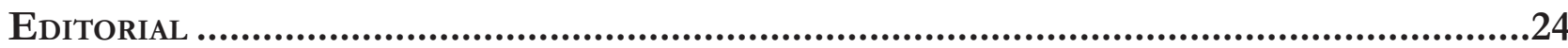

O Direito na fronteira da razão: Psicologia, neurociência e economia comportamental................... 24 Patrícia Perrone Campos Mello e Sergio Nojiri

I. NeURodireito: COGNIÇão, EMOÇÃo, JUÍZOS MORAIS E CIÊNCIA ..........................................26

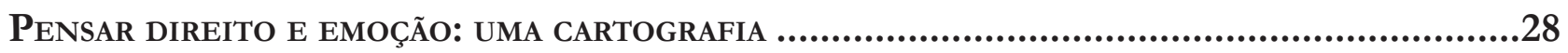

Nevita Maria Pessoa de Aquino Franca Luna

Neurodireito: o início, o fim E O MEIO

Carlos Marden e Leonardo Martins Wykrota

ENSAIO JURÍDICO SOBRE A RACIONALIDADE HUMANA: MAIORES, CAPAZES E IRRACIONAIS

André Perin Schmidt Neto e Eugênio Facchini Neto

DIVERGÊNCIAS DE PRINCÍPIO: ARGUMENTOS JURÍDICOS E MORAIS EM UM CENÁRIO DE DESACORDOS SOCIAIS

André Matos de Almeida Oliveira, Pâmela de Rezende Côrtes e Leonardo Martins Wykrota

CONSILIÊNCIA E A POSSIBILIDADE DO NEURODIREITO: DA DESCONFIANÇA À RECONCILIAÇÃO DISCIPLINAR.....

Thaís de Bessa Gontijo de Oliveira e Renato César Cardoso

MODELOS DE MORALIDADE

Molly J. Crockett

A INFELIZ BUSCA POR FELICIDADE No DiREITo

Úrsula Simões da Costa Cunha Vasconcellost, Noel Struchiner e Ivar Hannikainen

Além da liberdade: PersPeCtivas Em Nietzsche.

Lucas Costa de Oliveira

A mediaÇão de CONFlitos SOb a PERSPECTIVA do DESENVOLVIMENTO HUMANO: AS CONTRIBUIÇÕES DA PSICOLOGIA POSITIVA

Simone de Biazzi Ávila Batista da Silveira e Deise Brião Ferraz

Neuroimagiologia e aValiação de ResPonsabilidade

Nicole A. Vincent 
ANÁLISE CRÍTICA DA ORIENTAÇÃO DE CIDADÃOS COMO MÉTODO PARA OTIMIZAR DECISÕES PÚBLICAS POR MEIO DA TÉCNICA NUDGE.

Luciana Cristina Souza, Karen Tobias França Ramos e Sônia Carolina Romão Viana Perdigão

Políticas públicas e o deVer de monitoramento: “LEVANdo os Direitos A SÉrio". .252 Ana Paula de Barcellos

Nudges E POLÍticas PÚblicas: uM MECANISMO DE COMBATE AO TRABALHO EM CONDIÇÃo ANÁLOGA À DE ESCRAVO .267

Amanda Carolina Souza Silva, Débhora Renata Nunes Rodrigues e Saul Duarte Tibaldi

REDUZINDO A TRIBUTAÇÃO COGNITIVA: LIÇÕES COMPORTAMENTAIS PARA A DIMINUIÇÃO DOS EFEITOS PSICOLÓGICOS ADVERSOS DA POBREZA.............................................................288 Leandro Novais e Silva, Luiz Felipe Drummond Teixeira, Gabriel Salgueiro Soares e Otávio Augusto Andrade Santos

Políticas PÚBLICAS EM SUICÍDIO: DO PATERNALISMO CLÁSSICO AO PATERNALISMO LIBERTÁRIO E NUDGING

Davi de Paiva Costa Tangerino, Gabriel Cabral e Henrique Olive

Nudges COMO POLÍticA PÚbliCA PARA AUMENTAR O ESCASSO NÚMERO DE DOADORES DE ÓRGÃos PARA TRANSPLANTE

Roberta Marina Cioatto e Adriana de Alencar Gomes Pinheiro

Os PROGRAMAS DE INTEGRIDADE PARA CONTRATAÇÃO COM A ADMINISTRAÇÃO PÚBLICA ESTADUAL: NUDGE OU OBRIGAÇÃo LEGAL? UM OLHAR SOBRE AS DUAS PERSPECTIVAS .386

Cíntia Muniz Rebouças de Alencar Araripe e Raquel Cavalcanti Ramos Machado

Paternalismo libertário e Proteção JURídica do AMbiente: POR QUe PROTEger o AMBIENTE TAMBÉM DEVE SER PROTEGER AS LIBERDADES?

Mariana Carvalho Victor Coelho e Patryck de Araujo Ayala

Políticas PÚblicas baseadas EM EVIdÊNCIAS COMPORTAMENTAIS: REFLEXões A PARTIR do Projeto de Lei 488/2017 do Senado

Pâmela de Rezende Côrtes, André Matos de Almeida Oliveira e Fabiano Teodoro de Rezende Lara

III. ECONOMIA COMPORTAMENTAL: VIESES COGNITIVOS E POLÍTICAS PÚBLICAS .455

ECONOMIA COMPORTAMENTAL E DIREITO: A RACIONALIDADE EM MUDANÇA Marcia Carla Pereira Ribeiro e Victor Hugo Domingues

VIESES COGNITIVOS E DESENHO DE POLÍTICAS PÚBLICAS 
A neurociênCia da moralidade na tomada de DeCisões Jurídicas Complexas e No DESENHO DE POLÍTICAS PÚBLICAS

Erik Navarro Wolkart

Desvio de CARÁter ou SIMPLESMENTE HUMANO? ECONOMIA COMPORTAMENTAL APLICADA AO COMPORTAMENTO DESONESTO

Diana Orghian, Gabriel Cabral, André Pinto e Alessandra Fontana

Políticas Públicas e a ConcretizaÇão de direitos sociais: TOMAdA DE DECisão, ARQUITETURA DE ESCOLHAS E EFETIVIDADE

Ana Elizabeth Neirão Reymão e Ricardo dos Santos Caçapietra

BEHAVIORAL ECONOMICS E DIREITO DO CONSUMIDOR: NOVAS PERSPECTIVAS PARA O ENFRENTAMENTO DO SUPERENDIVIDAMENTO .568

Samir Alves Daura

A EDUCAÇÃo FORMAL PARA O CONSUMO É GARANTIA PARA UMA PRESENÇA REFLETIDA DO CONSUMIDOR NO MERCADO? UMA ANÁLISE COM BASE NA BEHAVIORAL LAW AND ECONOMICS (ECONOMIA COMPORTAMENTAL) 600

Marcia Carla Pereira Ribeiro e Edson Mitsuo Tiujo

LIBET, DETERMINISMO E CONSUMO: AS INFLUÊNCIAS DO MARKETING E A RELEVÂNCIA DA DELIBERAÇÃo CONSCIENTE NA SUPERAÇÃo CONDICIONAL DE HÁBITOS DE CONSUMO PERIGOSOS616 Émilien Vilas Boas Reis e Leonardo Cordeiro de Gusmão

CiÊNCIA DO DIREITO TRIBUTÁRIO, ECONOMIA COMPORTAMENTAL E EXTRAFISCALIDADE. .640 Hugo de Brito Machado Segundo

IV. CoMportamento JUdiCiAL: INFLUÊNCIA DE FATORES EXTRAJURÍDicos .660

FATORES METAPROCESSUAIS E SUAS INFLUÊNCIAS PARA A FORMAÇÃo DA DECISÃo JUDICIAL .662 Rogério Roberto Gonçalves de Abreu, Lúcio Grassi de Gouveia e Virgínia Colares

“A VIDA COMO ELA É": COMPORTAMENTO ESTRATÉGICO NAS CORTES Patrícia Perrone Campos Mello

A COMPOSIÇÃo do ÓRGão COLEGIAdo E SEUS EFEITOS NA TOMADA DE DECISÃo .720 André Garcia Leão Reis Valadares

Das 11 ilhas ao centro do arquipélago: os superpoderes do Presidente do STF DURANTE O RECESSO JUDICIAL E FÉRIAS .741 José Mário Wanderley Gomes Neto e Flávia Danielle Santiago Lima 
RAZÃo, EMOÇÃo E DELIBERAÇÃO: AS ADEQUAÇÕES REgIMENTAIS do SUPERIOR TribUNAL DE JUSTIÇA PARA A FORMAÇÃo DE PRECEDENTES EFICAZES

Peter Panutto e Lana Olivi Chaim

Heurística de ancoragem e fiXaÇÃo de danos morais em JUizados especiais Cíveis no Rio DE JANEIRO: UMA NOVA ANÁLISE 778

Fernando Leal e Leandro Molhano Ribeiro

LA PROTECCIÓN DE LOS DERECHOS POLÍTICOS FRENTE A LAS FUNCIONES DISCIPLINARIAS DE LAS AUTORIDADES ADMINISTRATIVAS: SUBSIDIARIEDAD Y DEFERENCIA EN EL SISTEMA INTERAMERICANO DE DERECHOS HUMANOS Jorge Ernesto Roa Roa

V. A influênCia do gÊNERo no PROCESSO DECisório JUdiCial

Como os Juízes decidem os Casos de estupro? ANALISANDo SENTENÇAS SOb A PERSPECTIVA DE VIESES E ESTEREÓTIPOS DE GÊNERO 826 Gabriela Perissinotto de Almeida e Sérgio Nojiri

GÊNERO E COMPORTAMENTO JUDICIAL NO SUPREMO TRIBUNAL FEDERAL: OS MINISTROS CONFIAM MENOS EM RELATORAS MULHERES?

Juliana Cesario Alvim Gomes, Rafaela Nogueira e Diego Werneck Arguelhes

Hércules, Hermes e a Pequena Sereia: uma reflexão sobre estereótipos de gênero, SUBPRESENTAÇÃo DAS MULHERES NOS TRIBUNAIS E (I)LEGITIMIDADE DEMOCRÁTICA DO PODER JUDICIÁRIO. .878 Jane Reis Gonçalves Pereira e Renan Medeiros de Oliveira

Prisão Cautelar de gestantes: análise do Fundamento filosófico da decisão do Habeas CoRpus N. 143.641 912

Artur César Souza e Giovania Tatibana de Souza

VI. Neurodireito APlicado ao direito E Ao Processo PENAL....................................926

CÉREbros QUe PUNEM: UMA REVISÃo CRÍTICA DA NEURoCIÊNCIA DA PUNIÇÃo .....................928 Ricardo de Lins e Horta

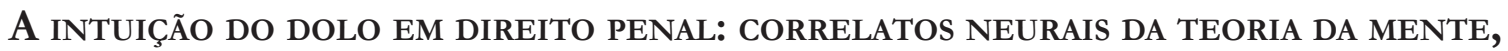
RACIOCÍNIO INDUTIVO E A GARANTIA DA CONVICÇÃO JUSTIFICADA. .946 Thiago Dias de Matos Diniz e Renato César Cardoso

As COMUNIDADES EPISTÊMICAS PENAIS E A PRODUÇÃo LEGISLATIVA EM MATÉRIA CRIMINAL..... 961 Stéphane Enguéléguélé 
DELINQUÊNCIA JUVENIL: RELAÇÕES ENTRE DESENVOLVIMENTO, FUNÇÕES EXECUTIVAS E COMPORTAMENTO SOCIAL NA ADOLESCÊNCIA .

André Vilela Komatsu, Rafaelle CS Costa e Marina Rezende Bazon

Límites TEMPORALES A LAS PENAS PRIVATIVAS DE LIBERTAD ATENDIENDO AL DESARROLLO PSICOSOCIAL.

Silvio Cuneo Nash

NEURolaw E AS PERSPECTIVAS PARA UMA ANÁLISE OBJETIVA DO COMPORTAMENTO SUGESTIONADO: REPERCUSSÃO DAS FALSAS MEMÓRIAS NA ESFERA PENAL

Mariana Dionísio de Andrade, Marina Andrade Cartaxo e Rafael Gonçalves Mota

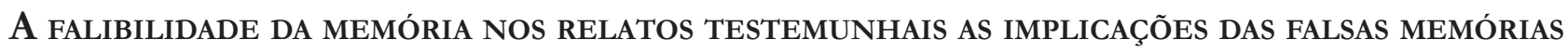
NO CONTEXTO DOS CRIMES CONTRA A DIGNIDADE SEXUAL

Caroline Navas Viana

A (IR)REPETIBILIDADE dA PROVA PENAL DEPENDENTE DA MEMÓRIA: UMA DisCUSSÃo COM BASE NA PSICOLOGIA DO TESTEMUNHO. 1058

William Weber Cecconello, Gustavo Noronha de Avila e Lilian Milnitsky Stein 


\title{
Heurística de ancoragem e fixação de danos morais em juizados especiais cíveis no Rio de Janeiro: uma nova análise*
}

\author{
Anchoring-and-adjustment heuristic and \\ the setting of moral damages in small claims \\ courts in Rio de Janeiro: a new analysis
}

\author{
Fernando Leal** \\ Leandro Molhano Ribeiro***
}

\section{Resumo}

O objetivo deste trabalho é investigar, empiricamente, a influência de fatores intuitivos na tomada de decisão jurídica. Especificamente, pretende-se medir a influência da heurística de ajuste e ancoragem sobre juízes provocados a fixar valores de indenização por danos morais causados em consumidores. Partiu-se da hipótese de que os valores pedidos pelas partes a título de indenização por dano moral atuam como âncoras para a fixação da indenização homologada pelo juiz. Essa hipótese geral foi testada a partir de casos reais em 524 processos dos I e II Juizados Especiais Cíveis da Regional Barra da Tijuca entre 2011 e 2014, a partir de informações exatas sobre os valores de indenização pedidos pelos consumidores e os valores de indenização deferidos na decisão judicial. Assim, a presente investigação avança em relação à análise anteriormente feita com o mesmo objetivo deste estudo, mas desenvolvida buscando correlacionar o valor da causa com os pedidos deferidos judicialmente. Embora os resultados encontrados indiquem que há, em geral, pouco efeito de ancoragem dos pedidos feitos pelas partes a título de indenização por danos morais na decisão do juiz, identificamos variações interessantes que podem indicar a influência de julgamentos intuitivos em determinadas situações: quando as partes pedem valores bem abaixo do teto legalmente permitido (o que significa, sendo mais preciso, quando os valores não excedem o valor mediano pedido nos processos) e quando pedem valores "quebrados". Foi feita, também, uma análise comparativa das relações entre valores pedidos e deferidos em grandes áreas ("telecomunicações", "varejo", "bancos" e "aéreas"). Nesse caso, observou-se que as correlações seguem o mesmo padrão geral de baixa correlação, exceto em "aéreas", cujo índice de correlação de Spearman alcança 0,57, o que sugere efeitos de ancoragem. Este último dado também representa um avanço em relação ao estudo anterior sobre ancoragem e danos morais, no qual setores específicos não foram analisados.

Palavras-chave: Heurísticas e vieses. Ancoragem. Raciocínio jurídico. Danos morais. Incerteza. Regulação.

*** Doutor e Mestre em Ciência Política pelo IUPERJ. Graduado em Ciências Sociais pela UFMG. Professor da Graduação e do Mestrado em Direito da Regulação da FGV Direito Rio.

E-mail: leandro.ribeiro@fgv.br

** Doutor em Direito pela Christian-Albrechts-Universität zu Kiel, com bolsa do Serviço Alemão de Intercâmbio Acadêmico (DAAD). em Direito Público pela UER. reito da Regulação da FGV Direito Rio. E-mail: fernando.leal@fgv.br 


\section{Abstract}

This study aims to assess the influence of intuitive aspects in judicial decision-making. More specifically, it intends the influence of the anchoring and adjustment heuristic over judges in cases involving the setting of moral damages involving consumer issues. The hypothesis we test is that the amount claimed by the parties in moral damages anchors the amount set in the sentence by the judge if the plaintiff wins. This general hypothesis has been tested in a sample composed by 524 real cases at the I and II Small Claims Courts (Juizados Especiais Cíveis) of the Barra da Tijuca region in Rio de Janeiro, between the years 2011 and 2014 on the basis of the exact amounts claimed by the plaintiffs and the final value attributed by judges. In this sense, this investigation goes forward in comparison to previous analysis with the same aim, but developed focusing on possible correlations between the amount attributed to the legal issue ("valor da causa") and the setting of moral damages. After the correlation tests, anchoring effects over the judicial decision could not be identified. However, there are interesting variations in the dataset that suggests that the decision-making context may somehow soften the possible effects of the anchoring and adjustment heuristic. Although we found a low correlation between the amounts attributed to the cases involving moral damages and the amounts the defendants were sentenced to pay, we identify some variations that might indicate the influence of intuitive judgements in certain situations: when the plaintiffs ask for an amount far below the legally permitted limit (i.e. when the value does not exceed the median value claimed in the cases) and when they claim non-zero decimal values. Moreover, we also compare the relationship between the amounts claimed and the amounts fixed by the judges in four big areas: telecommunications, retail, banks and aviation. In these scenarios, the analysis follows the same low correlation pattern, except in the aviation sector, in which the Spearman correlation index reaches 0,57 , what suggests anchoring effects in this area. This last finding represents also a step further in comparison to previous analysis on anchoring effects and moral damages, since it doesn't focus on specific sectors.

Keywords: Heuristics and biases. Anchoring. Legal reasoning. Damages in personal injury cases. Uncertainty. Regulation.

\section{INTRODUÇÃo}

\subsection{Teorias normativas e limites reais para a tomada de decisão}

Teorias jurídicas costumam ser empreendimentos normativos. Elas almejam orientar as práticas nos espaços de criação e aplicação do direito por meio de prescrições sobre como, por exemplo, legisladores devem atuar, como o processo legislativo deve se organizar, como juízes devem se comportar quando são provocados a rever atos de outros poderes, como a Constituição deve ser interpretada e como o administrador público deve justificar as suas escolhas. Com essas pretensões, teorias jurídicas são construídas comumente visando aproximar a realidade de algum estado ideal de coisas, justificado em nome da realização de objetivos social ou politicamente relevantes ${ }^{1}$, ou mesmo com base em exigências supostamente conceituais ${ }^{2}$.

1 Tome-se como exemplo o tipo de teoria sobre a qual se constrói o constitucionalismo brasileiro da efetividade, que prescreve como os aplicadores da Constituição devem lidar com os seus comandos a partir de uma preocupação com a realização da maior efetividade constitucional. V. sobre o assunto SOUZA NETO, Cláudio Pereira de. Fundamentação e normatividade dos direitos fundamentais: uma reconstrução teórica à luz do princípio democrático. In: BARROSO, Luís Roberto (Org). A nova interpretação constitucional: ponderação, direitos fundamentais e relações privadas. Rio de Janeiro: Renovar, 2006. e BARROSO, Luís Roberto. A doutrina brasileira da efetividade. In: BARROSO, Luís Roberto. (Org.). O direito constitucional e a efetividade de suas normas: limites e possibilidades da Constituição brasileira. 8. ed. Rio de Janeiro: Renovar, 2006.

2 V. como exemplo o projeto de institucionalização de Robert Alexy e a sua relação com a sua concepção da dupla natureza do 
No primeiro caso, teorias normativas se justificariam na medida em que recomendariam a adoção de certos comportamentos considerados necessários para a promoção de alguma concepção de objetivos relevantes como a justiça social, a igualdade, a separação de poderes, a democracia ou a liberdade ${ }^{3}$. No segundo caso, agir da forma prescrita pela teoria é considerado uma necessidade para que se possa continuar a chamar certa prática social, norma ou conjunto normativo de, por exemplo, "jurídica" ou "democrática".

A construção de teorias normativas, no entanto, é cercada por riscos permanentes. O principal deles é o de descolamento com a realidade. Esse pode se dar por duas razões: por diagnósticos imperfeitos ou por idealização. Por um lado, teorias normativas podem partir de diagnósticos imprecisos ou simplesmente falsos sobre o mundo. A realidade problemática que se pretende alterar por meio das prescrições da teoria, com outras palavras, pode ser completamente diferente daquela pressuposta pelo modelo teórico que ergue a pretensão de partir de uma descrição confiável do mundo. Recomenda-se, por exemplo, que o Judiciário deve ser sempre deferente a escolhas regulatórias em razão das suas reduzidas capacidades institucionais quando, no mundo real, o que se constata pode ser exatamente um déficit de capacidade institucional de certa Agência Reguladora (por não estar, por exemplo, com o seu quadro técnico completo e por estar politicamente capturada) relativamente às capacidades apreensíveis de um órgão do Poder Judiciário organizado e no qual especialistas confiáveis são chamados a se manifestar sobre a solução de temas complexos ${ }^{4}$. Nesse caso, o problema da prescrição é de tentar lidar com um problema, de fato, inexistente. Com isso, corre-se o risco de orientar a realidade para um ponto não necessariamente melhor. Por outro lado, a segunda maneira pela qual um descolamento com a realidade pode se dar na construção de teorias normativas está relacionada às idealizações que informam as prescrições. A teoria, nesse caso, pode ser simplesmente irrelevante para alterar a realidade na direção por ela visada porque pressupõe agentes ideais ou ambientes ideais nos quais agentes (reais ou ideais) decidem. Em ambos os casos, a importância efetiva da teoria para conduzir a prática decisória se dilui, permanecendo, no máximo, o seu potencial crítico.

As dificuldades apontadas que parecem afetar, tradicionalmente, teorias jurídicas normativas não são novidades, porém, na economia. Herbert Simon, em meados do século passado, denunciou o baixo interesse em microeconomia descritiva. Para Simon, entender o comportamento de agentes econômicos individuais se limitava ao necessário para fornecer as bases para construções macroeconômicas normativas 5 . Havia, nesse sentido, apenas, a pressuposição de uma teoria pouco desenvolvida sobre o comportamento humano, alicerçada sobre como as pessoas devem decidir. A normatividade de teorias econômicas se sustentava, assim, sobre pressupostos também normativos. Com isso, fortes previsões sobre o comportamento humano eram feitas sem que pessoas reais fossem observadas. ${ }^{6}$ Nas palavras de Simon: "a teoria clássica [que assumia a racionalidade de agentes econômicos e competição perfeita $\left.{ }^{7}\right]$ é a teoria de um indivíduo escolhendo entre alternativas postas e conhecidas, para cada qual são vinculadas consequências conhecidas. No entanto, quando percepção e cognição intervêm entre o tomador de decisão e o seu ambiente objetivo, esse modelo não se prova mais adequado. Precisamos de uma descrição do processo de escolha que reconhece que alternativas

direito. Cf. ALEXY, Robert. Principais elementos de uma teoria da dupla natureza do direito. Revista de Direito Administrativo, n. 253, p. 9-29, 2010.

3 Como exemplo, v. a prescrição sugerida para a atuação judicial em uma teoria sobre a legitimidade da jurisdição constitucional conceitualmente compatível com diferentes concepções sobre democracia de BARROSO, Luís Roberto. A razão sem voto. Revista Brasileira de Políticas Públicas, v. 5, n. esp., p. 23-50, 2015.

4 Sobre os problemas relacionados à criação de nirvanas institucionais pela ausência de base empírica v. ARGUELHES, Diego Werneck; LEAL, Fernando. O argumento das “capacidades institucionais” entre a banalidade, a redundância e o absurdo. Direito, Estado e Sociedade, n. 38, p. 6-50, jan./jun. 2011. p. 41.

5 SIMON, Herbert A. Theories of decision-making in economics and behavioral science. The American Economic Review, v. 49, n. 3, p. 253-283, jun. 1959. p. 254.

6 SIMON, Herbert A. Theories of decision-making in economics and behavioral science. The American Economic Review, v. 49, n. 3, p. 253-283, jun. 1959. p. 254.

7 SIMON, Herbert A. Theories of decision-making in economics and behavioral science. The American Economic Review, v. 49, n. 3, p. 253-283, jun. 1959. p. 254. V. também SIMON, Herbert A. A behavioral model of rational choice. The Quarterly Journal of Economics, v. 69, n. 1, p. 99-118, fev. 1955. p. 99. 
não são dadas, mas devem ser procuradas; e uma descrição que considera a ardorosa tarefa de determinar quais consequências se seguirão de cada alternativa". ${ }^{8}$ Dado esse possível descompasso entre o que se assume correto e o que pode ser verdadeiro sobre a tomada de decisão humana, base empírica sobre como as pessoas realmente enfrentam e decidem problemas passa a ser crucial para o sucesso de teorias prescritivas. Por isso, para Simon, o quanto a economia depende de diálogos com a psicologia depende, entre outros fatores, de até que ponto podemos confiar na suposição de que é possível se aproximar desse ideal de decisor?.

É exatamente por ser questionável a descrição do comportamento humano como perfeitamente racional e a suposição de que podemos reunir e processar informações sobre o nosso ambiente em contextos reais de tomada de decisão que Simon cunhou a expressão racionalidade limitada. Por meio desse rótulo, expressa-se a concepção de que tomadores de decisão "de carne e osso" (i) não são seres necessariamente maximizadores de suas preferências e (ii) não possuem a capacidade computacional de processamento nem o acesso às informações necessárias para agir dessa maneira ${ }^{10}$. Seres humanos reais, ao contrário do que o conceito de homo economicus pressupõe, tendem a ajustar as suas aspirações ao atingível ${ }^{11}$. Às vezes, o curso de ação privilegiado por pessoas reais é aquele que produz um resultado considerado "bom o suficiente", o que sugere que o comportamento maximizador é, em diversos momentos, substituído pela satisfação com o que se revela suficiente em dado contexto decisório. Assim, no modelo de racionalidade limitada proposto por Simon, a maximização da utilidade é substituída pela disposição ao comportamento "satissuficiente" (satisficing) ${ }^{12}$.

Esse ataque lançado contra os pressupostos da economia clássica inspirou uma longa agenda de pesquisa empírica preocupada com o mapeamento da racionalidade limitada. Nesse aspecto, os trabalhos desenvolvidos por Daniel Kahneman e Amos Tversky desempenham um papel central, na medida em que buscam explorar os vieses sistemáticos que separam (i) as crenças que as pessoas possuem e as escolhas que eles realizam (ii) das crenças ótimas pressupostas por modelos inspirados em agentes plenamente racionais ${ }^{13}$.

Essa é, sem dúvida, uma longa história. E, ao contrário do que possa parecer, sua utilidade não se limita à necessidade de um repensar de certos pressupostos de modelos econômicos. Porque teorias jurídicas também são tradicionalmente construídas idealizações e negligenciam descrições acuradas sobre a realidade e o comportamento humano, elas podem igualmente estar sujeitas a críticas (i) por menosprezarem as condições de racionalidade limitada sob as quais pessoas reais decidem problemas e (ii) não atentarem para os vieses de julgamento a que essas pessoas estão sujeitas quando são chamadas a decidir ${ }^{14}$. Este é o ponto de partida para justificar por que agendas de pesquisa empírica preocupadas com processos reais de tomada de decisão deveriam também passar a ocupar as preocupações de juristas.

8 SIMON, Herbert A. Theories of decision-making in economics and behavioral science. The American Economic Review, v. 49, n. 3, p. 253-283, jun. 1959. p. 272.

9 SIMON, Herbert A. Theories of decision-making in economics and behavioral science. The American Economic Review, v. 49, n. 3, p. 253-283, jun. 1959. p. 279.

10 SIMON, Herbert A. A behavioral model of rational choice. The Quarterly Journal of Economics, v. 69, n. 1, p. 99-118, fev. 1955. p. 99.

11 SIMON, Herbert A. Theories of decision-making in economics and behavioral science. The American Economic Review, v. 49, n. 3, p. 253-283, jun. 1959. p. 263.

12 V. KAHNEMAN, Daniel. Maps of bounded rationality: psychology for behavioral economics. The American Economic Review, v. 93, n. 5, p. 1449-1475, dez. 2003. p. 1449. V. tb. VERMEULE, Adrian. Three strategies of interpretation. San Diego Law Review, v. 42, p. 607-628, 2005.

13 V. KAHNEMAN, Daniel. Maps of bounded rationality: psychology for behavioral economics. The American Economic Review, v. 93, n. 5, p. 1449-1475, dez. 2003. p. 1449.

14 Para uma articulação entre estudos de economia comportamental para a adequada regulação ambiental v. BASTIANETTO, Lorena Machado Rogedo; GOMES, Magno Federici. Regulação ambiental da atividade minerária: uma análise econômica de compliance. Revista Brasileira de Políticas Públicas, v. 1, n. 1, p. 207-219, 2017. 


\subsection{Propósito do trabalho e colocação do problema de pesquisa}

No contexto apresentado, o presente trabalho propõe uma investigação empírica sobre a influência de fatores intuitivos na tomada de decisão jurídica. O que se pretende é obter um diagnóstico confiável a respeito da interferência de erros de julgamento provocados por sugestões, ainda que inconscientes, de participantes do discurso jurídico na tomada de decisão judicial. Mais especificamente, o texto dialoga com pesquisa anterior destinada a medir a influência da heurística de ajuste e ancoragem sobre juízes provocados a fixar valores de indenização por danos morais causados em consumidores. ${ }^{15}$

Heurísticas podem ser definidas como regras de experiência que permitem a tomada de decisão rapidamente a baixo custo. São atalhos que sugerem respostas quase automáticas (intuitivas, portanto) para problemas com base em padrões fixados com base em vivências anteriores. Graças ao papel desempenhado por essas regras na tomada de decisão, não precisamos mobilizar uma grande quantidade de recursos para enfrentar todos os problemas com os quais nos deparamos diariamente ${ }^{16}$. Fazê-lo envolveria custos proibitivos. Contudo, se, por um lado, a observância de heurísticas implica vantagens para a ação de seres que não detêm capacidade infinita para processar informações e atuam em um ambiente repleto de limitações, por outro, o resultado da aplicação dessas regras de experiência nem sempre nos leva ao julgamento correto, i.e., ao resultado a que chegaríamos se desativássemos esse lado intuitivo com base no qual o cérebro funciona corriqueiramente. Essas falhas de julgamento causadas pela observância de padrões intuitivos são chamadas de vieses cognitivos.

Investigar quais são as heurísticas e como vieses interferem nos processos humanos de tomada de decisão sob condições de incerteza está no centro do programa de pesquisa desenvolvido por Kahneman e Tversky ${ }^{17}$. Uma dessas heurísticas é a de ajuste e ancoragem ou simplesmente heurística de ancoragem. Como já tivemos a oportunidade de esclarecer, a ancoragem está relacionada ao "efeito causado pela confiança intuitivamente atribuída a um número dado" quando somos chamados a dar respostas numéricas em cenários de incerteza ${ }^{18}$. Nessas condições, o cérebro começaria a calibrar uma resposta com base em ajustes efetuados tomando como ponto de partida o número de referência. Suponha, por exemplo, que alguém seja submetido à seguinte pergunta: de acordo com o último registro divulgado, quantos livros estão catalogados no sistema da biblioteca do Congresso dos EUA, considerada a maior do mundo? Essa parece ser uma questão difícil exatamente porque, muito provavelmente, o interrogado não faz muita ideia do número exato. No entanto, talvez fizesse alguma diferença para a resposta se a mesma questão fosse formulada nos seguintes termos: de acordo com o último registro divulgado, quantos livros estão catalogados no sistema da biblioteca do Congresso dos EUA, considerada a maior do mundo: mais ou menos de 8 milhões? Agora com o referencial numérico (a âncora que atrai o julgamento), espera-se que o número indicado seja menor do que aquele que seria obtido caso a referência fosse alterada para, por exemplo, 56 milhões ${ }^{19}$. A razão

15 LEAL, Fernando; RIBEIRO, Leandro Molhano. O direito é sempre relevante? Heurística de ancoragem e fixação de valores indenizatórios em pedidos de dano moral em juizados especiais do Rio de Janeiro. Direitos Fundamentais e Justiça, Belo Horizonte, a. 10, n. 35, p. 253-284, jul./ dez. 2016.

16 V. KAHNEMAN, Daniel. Maps of bounded rationality: psychology for behavioral economics. The American Economic Review, v. 93, n. 5, p. 1449-1475, dez. 2003. p. 1450, para quem “ (i) a maior parte dos juízos e as escolhas são feitos intuitivamente e (ii) as regras que governam a instituição são comumente similares às regras de percepção”.

17 KAHNEMAN, Daniel. Maps of bounded rationality: psychology for behavioral economics. The American Economic Review, v. 93, n. 5, p. 1449-1475, dez. 2003. p. 1449. V. também KAHNEMAN, Daniel. Rápido e devagar: duas formas de pensar. Objetiva: Rio de Janeiro, 2012. KAHNEMAN, Daniel; SLOVIC, Paul; TVERSKY, Amos. Judgment under uncertainty: heuristics and biases. New York: Cambridge University Press, 1982.

18 LEAL, Fernando; RIBEIRO, Leandro Molhano. O direito é sempre relevante? Heurística de ancoragem e fixação de valores indenizatórios em pedidos de dano moral em juizados especiais do Rio de Janeiro. Direitos Fundamentais e Justiça, Belo Horizonte, a. 10 , n. 35 , p. 253-284, jul./ dez. 2016. p. 259.

19 De acordo com o site da biblioteca, o número exato é de 24.356 .449 livros catalogados. V. ESTADOS UNIDOS DA AMÉRICA. Library of Congress. General information. Disponível em: < https://www.loc.gov/about/general-information/\#year-at-aglance>. Acesso em: 22 maio 2018. 
dessa diferença é simplesmente o efeito causado pela âncora.

Verificar a influência dessa heurística nos valores fixados a título de danos morais em questões de consumo constituiu o objetivo central da nossa primeira pesquisa e segue sendo o objetivo central do presente trabalho. No entanto, dessa vez a pesquisa pretende avançar por duas razões centrais. Em primeiro lugar, as investigações serão feitas no presente estudo com base no valor efetivamente pedido pelas partes, e não apenas com base no valor da causa, único dado disponível quando da realização da primeira análise. Em segundo lugar, em função da qualidade da nova base, foi possível diferenciar, em razão da matéria levada a julgamento em Juizados Especiais Cíveis, setores específicos (no caso, os setores de varejo, telecomunicações, bancário e aéreo), no âmbito do qual correlações entre valor pedido e valor deferido puderam ser especificamente buscadas. Sem embargo desses novos passos, o problema que guiará a presente pesquisa segue podendo ser formulado da seguinte maneira: é possível constatar o efeito de ancoragem nos valores deferidos a título de danos morais em processos judiciais reais? À época, a escolha pela investigação no universo dos danos morais se justificou nos seguintes termos:

este nos pareceu um tipo de problema plenamente adequado para a verificação de efeito de ancoragem, uma vez que a fixação de dano moral pressupõe análises particularistas relacionadas a eventuais restrições a direitos fundamentais que não são claramente parametrizadas por regras do direito. Havendo, portanto, altas margens de liberdade para o magistrado, pretendemos investigar, no fundo, se, para a fixação do quantum devido, dada a indeterminação do direito, como a psicologia cognitiva sugere, os juízes são simplesmente enviesados a ajustar os valores deferidos em função do pedido formulado pela parte - o que pode ser, por exemplo, um obstáculo para a efetiva concretização da proteção ao consumidor como garantia constitucional ${ }^{20}$.

Para além da adequação temática, as investigações apresentadas neste texto voltadas a constatar a eventual influência de fatores intuitivos na tomada de decisão judicial também se justificam pela tentativa de levá-las adiante com base em casos reais. Nesse sentido, a pesquisa desenvolvida escapa da proposta tradicional de trabalhos voltados a estudar heurísticas e vieses ${ }^{21}$, que partem da realização de experimentos controlados. Assim, por exemplo, fizeram, em relação à heurística de ancoragem, tanto Guthrie, Rachlinski e Wistrich ${ }^{22}$, como Englich, Mussweiler e Strack ${ }^{23}$.

20 LEAL, Fernando; RIBEIRO, Leandro Molhano. O direito é sempre relevante? Heurística de ancoragem e fixação de valores indenizatórios em pedidos de dano moral em juizados especiais do rio de janeiro. Direitos Fundamentais e Justiça, Belo Horizonte, a. 10, n. 35, p. 253-284, jul./ dez. 2016. p. 261.

21 Uma exceção é o trabalho de FARIÑA, Francisca; ARCE, Ramón; NOVO, Mercedes. Anchoring in judicial decision-making. Psychology in Spain, v. 7, n. 1, p. 56-65, 2003. No texto, os autores analisam 555 decisões criminais, proferidas entre 1980 e 1995 , de cortes superiores e cortes criminais da região autônoma da Galícia. O objetivo do estudo era investigar a influência do tempo pedido de condenação do promotor sobre a decisão judicial e, em casos de recurso, da decisão judicial anterior sobre a decisão do órgão ad quem. Em conclusão, os autores localizaram que 63,6\% dos casos são dirigidos por efeitos de ancoragem produzidos pelos pedidos da promotoria e pela decisão judicial do tribunal a quo (p. 60).

22 GUTHRIE, Chris; RACHLINSKI, Jeffrey; WISTRICH, Andrew. Blinking on the bench: how judges decide cases. Cornell Law Faculty Publications, v. 93, paper 917, p. 1-43, 2007. p. 20. Os autores submeteram dois grupos de juízes a um mesmo caso envolvendo um acidente de trânsito e, ao final, pediam que cada um deles fixasse um valor indenizatório. Como expusemos anteriormente, "[n]a situação, o autor da ação quebrou três costelas e sofreu graves danos no seu braço direto. Em razão dos danos, o autor ficou uma semana no hospital e perdeu, no total, seis semanas de trabalho. Para os juízes do grupo de controle, a única informação passada além dos fatos do caso foi a de que o autor pretende obter "uma reparação monetária significativa". Para outro grupo de magistrados, no entanto, foi dito que o autor reivindicava uma indenização de dez milhões de dólares. Os resultados, não surpreendentemente, confirmam o poder da âncora. Enquanto os magistrados do grupo de controle atribuíram, na média, uma indenização de 808.000 dólares, com mediana de 700.000 dólares, os juízes expostos à âncora defeririam, na média, o valor de 2.210 .000 de dólares, com mediana de um milhão de dólares. Do ponto de vista das informações fornecidas aos dois grupos, apenas o valor pedido era diferente, o que confirma o viés de ancoragem nas manifestações dos juízes". V. LEAL, Fernando; RIBEIRO, Leandro Molhano. O direito é sempre relevante? Heurística de ancoragem e fixação de valores indenizatórios em pedidos de dano moral em juizados especiais do Rio de Janeiro. Direitos Fundamentais e Justiça, Belo Horizonte, a. 10, n. 35, p. 253-284, jul./ dez. 2016. p. 260. 23 ENGLICH, Birte; MUSSWEILER, Thomas; STRACK, Fritz. Playing dice with criminal sentences: the influence of irrelevant anchors on expert's judicial decision-making. Personality and Social Psychology Bulletin, v. 32, n. 2, p. 188-200, fev. 2006. Nesse trabalho, investigou-se a influência de âncoras sobre os valores de penas sugeridas em três contextos diferentes: por um jornalista, por um pedido aleatório (sendo esse dado claramente informado aos participantes do experimento) feito por um promotor e por uma referência a que os próprios participantes do experimento teriam que chegar após jogarem um par de dados viciados a sempre 


\subsection{Hipótese, metodologia e conclusões da primeira análise}

Para enfrentar o problema de pesquisa colocado, partimos da hipótese de que seria constatável o efeito de ancoragem nos valores fixados a títulos de danos morais por juízes em processos reais, ainda que o efeito da âncora pudesse variar quando as correlações fossem exploradas em setores específicos, como questões envolvendo problemas bancários, no setor de varejo ou de telefonia. Com outras palavras, esperava-se encontrar correlações relevantes entre os valores de danos morais pedidos pelas partes e os valores deferidos pelos julgadores.

Para testar a hipótese, analisamos, no primeiro trabalho, 1.102 processos dos I e II Juizados Especiais Cíveis da Barra da Tijuca, localizados no Rio de Janeiro. Os casos foram julgados entre os anos de 2004 e 2015. Naquele momento, porém, como já antecipado, a base de dados sobre a qual a análise foi feita não incluía qualquer referência aos valores pedidos pelas partes, mas tão somente aos valores atribuídos às causas, que não necessariamente correspondem aos primeiros. Ainda assim, assumindo que eventual diferença entre "valor pedido" e "valor da causa" poderia ser reduzida no âmbito de causas levadas a julgamento em Juizados Especiais ${ }^{24}$, diversas análises de correlação foram feitas.

As conclusões, ainda que, repita-se, baseadas no valor da causa, indicaram, em um primeiro momento, a inexistência de influência de heurística de ancoragem no total de casos analisados. No entanto, análises mais específicas revelaram correlações mais fortes entre o valor da causa e o valor pedido quando (i) os valores das causas estavam mais distantes dos tetos de 20 e 40 salários mínimos e, em especial, quando eles eram mais baixos ${ }^{25}$ (o que sugeriu, como hipótese explicativa, que os limites impostos pela lei 9.099/95 para litigar sem e com advogado neutralizam, na prática, os efeitos das âncoras, ao despertarem no magistrado um olhar mais cuidadoso sobre a questão discutida) e (ii) quando as partes autoras pediam valores "quebrados"26 (o que, em mais uma possível explicação, pode sugerir que valores quebrados facilitam o efeito da âncora por erguerem a pretensão de serem produto de uma análise mais precisa e, portanto, confiável do dano efetivamente sofrido). Finalmente, constatou-se que um dos possíveis motivos pelos quais não se identificou a influência da heurística de ancoragem nos casos pode estar relacionado à adoção, pelo magistrado, de um tabelamento linear de danos morais, ou seja, da atribuição de valor único para uma série de casos que não necessariamente são próximos entre si. Este, no entanto, antes de ser um achado positivo das análises empreendidas, uma vez que refutariam a influência de fatores intuitivos nos julgamentos, revelam um tratamento disfuncional do instituto "dano moral", que exige análises particularistas e se mostra, assim, conceitualmente incompatível com a atribuição de um valor único para situações diferentes que envolvem lesões diferentes à personalidade ${ }^{27}$.

fornecerem os mesmos números (para um grupo os números eram sempre 1 e 2, enquanto para o outro grupo, os números eram 3 e 6). No primeiro caso, participaram do experimento 23 juízes e 19 promotores; no segundo, 37 juízes e 2 promotores; no terceiro, 52 bacharéis em direito que participavam de um programa de pós-graduação na German University of Administrative Sciences, em Speyer. Um quarto experimento foi realizado, ainda, em um cenário muito parecido com o terceiro experimento, mas, dessa vez, com 57 bacharéis recém-formados que tinham recentemente adquirido as suas primeiras experiências como juízes. Todos os participantes foram divididos, em cada experimento, em grupos e submetidos a diferentes âncoras em casos criminais cujas sugestões de penas variavam. Como conclusão, constatou-se que âncoras claramente irrelevantes produzem efeitos de ancoragem de similar magnitude aos de âncoras claramente relevantes (p. 198).

24 LEAL, Fernando; RIBEIRO, Leandro Molhano. O direito é sempre relevante? Heurística de ancoragem e fixação de valores indenizatórios em pedidos de dano moral em juizados especiais do Rio de Janeiro. Direitos Fundamentais e Justiça, Belo Horizonte, a. 10 , n. 35, p. 253-284, jul./ dez. 2016. p. 268, nota 22.

25 LEAL, Fernando; RIBEIRO, Leandro Molhano. O direito é sempre relevante? Heurística de ancoragem e fixação de valores indenizatórios em pedidos de dano moral em juizados especiais do Rio de Janeiro. Direitos Fundamentais e Justiça, Belo Horizonte, a. 10, n. 35, p. 253-284, jul./ dez. 2016. p. 271.

26 LEAL, Fernando; RIBEIRO, Leandro Molhano. O direito é sempre relevante? Heurística de ancoragem e fixação de valores indenizatórios em pedidos de dano moral em juizados especiais do Rio de Janeiro. Direitos Fundamentais e Justiça, Belo Horizonte, a. 10, n. 35, p. 253-284, jul./ dez. 2016. p. 276.

27 LEAL, Fernando; RIBEIRO, Leandro Molhano. O direito é sempre relevante? Heurística de ancoragem e fixação de valores indenizatórios em pedidos de dano moral em juizados especiais do Rio de Janeiro. Direitos Fundamentais e Justiça, Belo Horizonte, 


\section{O PRESENTE ESTUDO}

Na nova análise que se propõe, parte-se do mesmo problema de pesquisa e da mesma hipótese. A diferença desta vez, porém, reside no fato de as análises propostas serem feitas, efetivamente, com base no valor pedido pelas partes, e não mais apenas a partir do valor da causa. Além disso, foi possível diferenciar os casos analisados por setores específicos, o que permitiu investigar se o efeito de ancoragem poderia variar em razão do assunto levado a julgamento.

\subsection{Os dados dos I e II Juizados Especiais Cíveis da Regional Barra da Tijuca e a definição dos processos a serem analisados}

A análise se baseou em informações inicialmente disponibilizadas pelos I e II Juizados Especiais Cíveis da Regional Barra da Tijuca sobre processos de pedidos de danos morais entre os anos de 2004 e 2015. A base de dados disponibilizada pelos juizados é formada por 30.620 processos de pedidos de danos morais, contendo as seguintes informações:

- Código Processo;

- Valor Causa (Valor pedido no processo. Os valores foram atualizados pelo Índice Geral de Preços para valores de 2015);

- Comarca (Todos os processos são da Regional da Barra da Tijuca);

- Nome da Serventia;

- Data da Primeira Distribuição;

- Valor Condenação/Homologação (Valor da condenação ou da homologação. Não há uma informação sobre os processos em que houve um ou outro caso. Os valores foram atualizados pelo Índice Geral de Preços para valores de 2015);

- Nome Classe (Todos os dados referem-se a "Procedimento do Juizado Civil/Fazendário");

- Código Assunto (Códigos que se referem aos assuntos: 30.016=Dano Moral - Outros/Indenização por Dano Moral ou 30.006 Dano Moral Outros - CDC);

- Nome Assunto (Os assuntos disponibilizados são Dano Moral - Outros/Indenização por Dano Moral ou Dano Moral Outros - CDC);

- Nome Competência (Todos os processos são do Juizado Especial Cível);

- Nome da Serventia (Os processos são do Cartório do I Juizado Especial Cível ou do Cartório do II Juizado Especial Cível);

- Código do Andamento (do processo);

- Nome do Andamento (Apensação; Arquivamento; Ato Ordinatório Praticado; Conclusão ao Juiz; Conclusão ao Juiz Tabelar; Conclusão ao Juiz Vinculado; Decisão em Audiência; Decurso de Prazo; Desentranhamento; Desentranhamento de Mandado; Despacho em Audiência; Digitação de Carta Precatória; Digitação de Documentos; Envio Automático de Documento Eletrônico; Envio de Documento Eletrônico; Expedição de Documentos; Início da Execução; Juntada; Juntada de AR; Juntada de Mandado; Pedido de Desarquivamento; Publicação de Edital; Remessa; Remessa ao Juiz

a. 10, n. 35 , p. 253-284, jul./ dez. 2016. p. 281. 
Leigo; Sentença em Audiência; Trânsito em Julgado; Vista ao Advogado);

- Código (Código referente a cada um dos andamentos listados acima);

- $\quad$ Nome do Tipo do Ato do Andamento (Assinatura, Decisão, Despacho ou Sentença);

- Código do Tipo do Ato do Andamento (Código referente a cada ato do andamento listados acima)

- Código do Ato do Juiz do Andamento;

- $\quad$ Descrição do Ato do Juiz do Andamento;

- Data do Início do Andamento.

Com base nesses dados, se extraíram os processos analisados no primeiro estudo sobre a eventual influência da heurística de ancoragem nas decisões judiciais. $\mathrm{Na}$ ocasião, foram considerados para análise, apenas, os processos cujos pedidos tinham sido deferidos, o que correspondeu a 1.343 processos do total de 30.620 processos disponibilizados pelos juizados. Desses 1.343 foram ainda retirados todos os processos que apresentaram fortes indícios de problemas de registro, o que resultou em uma base de dados final com 1.102 processos com provimento entre 2004 e 2015.

Uma limitação do estudo anterior, como indicado, era a impossibilidade de saber exatamente os valores de danos morais pedidos e concedidos, uma vez que essas informações estavam agregadas, respectivamente, nas informações "valores da causa" e "valores da condenação" constantes na base de dados disponibilizada. Para este estudo, contudo, foi possível obter diretamente dos processos eletrônicos os valores de indenização por danos morais pedidos pelas partes do processo, assim como os valores exatos de indenização deferidos pelos juízes. Por isso, este estudo se baseia em um conjunto de processos retirado dos 1.343 processos selecionados para o estudo anterior. A justificativa para não considerar apenas os 1.102 processos da base de dados final anterior se deve à possibilidade de conferir, na própria fonte, os dados originais sobre os pedidos de danos morais e, se fosse o caso, corrigi-los.

Em relação aos 1343 processos, cinco foram descartados após a observação de que houve acordo entre as partes homologado judicialmente, o que resultou em uma base de dados inicial com 1.338 casos. A distribuição anual desses processos pode ser visualizada no gráfico abaixo. Nele, observa-se o reduzido número de processos com deferimento até 2007 nos dois juizados analisados. Entre 2008 e 2010, tem-se uma elevação no número de processos, que atinge um pico de mais de 500 processos em 2011. A partir de 2011, contudo, a quantidade de processos cai significativamente. 
Gráfico 1- Distribuição anual dos processos: número de processos entre 2004 e 2104

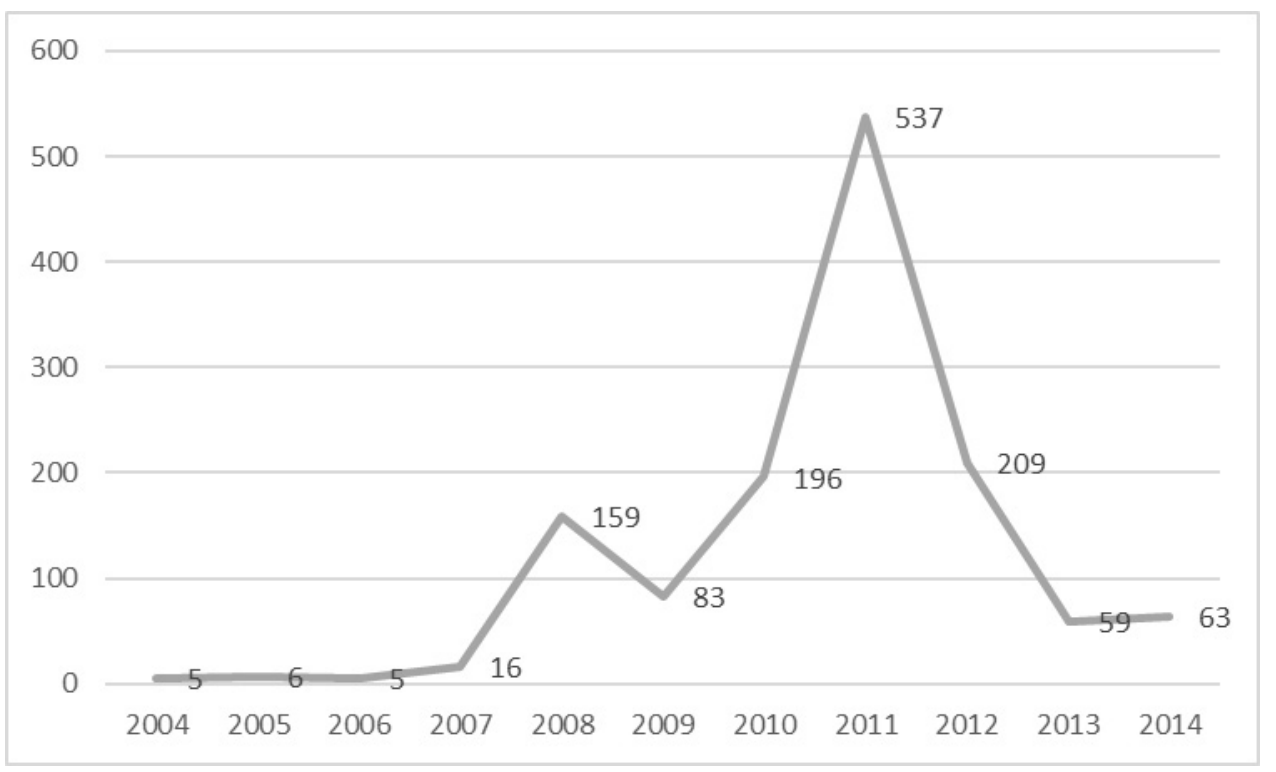

Fonte: TJRJ. Elaboração própria.

Como o objetivo da pesquisa é o teste da hipótese de ancoragem em decisões judiciais envolvendo pedidos de danos morais, foi necessário identificar os valores exatos de indenização pedidos pelas partes, assim como os valores de indenização deferidos pelos juízes. A pesquisa realizada para essa identificação foi feita em 683 processos eletrônicos. Ou seja, foram deixados de fora da análise 655 processos distribuídos nos juizados no formato não eletrônico.

Em relação aos 683 processos eletrônicos, constatou-se que 159 não tinham pedidos de danos morais diretamente formulados pelas partes. Nesses casos, foi pedido que o próprio juiz fixasse o valor de dano moral, o que inviabiliza a análise de influência da heurística de ancoragem, que pressupõe a identificação de um referencial (a "âncora") que afeta o julgamento. Assim, foram coletadas informações de 524 processos com pedidos de indenização de danos morais e que, potencialmente, poderiam ser usados na análise a respeito da influência da heurística de ancoragem. A distribuição anual desses 683 processos (sendo 524 com dados de pedidos de danos morais — "com âncora" - e 159 "sem âncora) pode ser observada no gráfico abaixo. Observa-se que os processos eletrônicos se iniciam em 2011, momento de pico de pedidos de indenização por danos morais nesses juizados, como foi apresentado no gráfico anterior., Dados de 2004 a 2010, portanto, não foram incluídos na análise. Em 2012 há uma forte queda na quantidade de processos, tendência que permanece, embora de forma bem menos acentuada, nos anos seguintes. 
Gráfico 2 - Distribuição anual dos processos eletrônicos: com e sem âncora

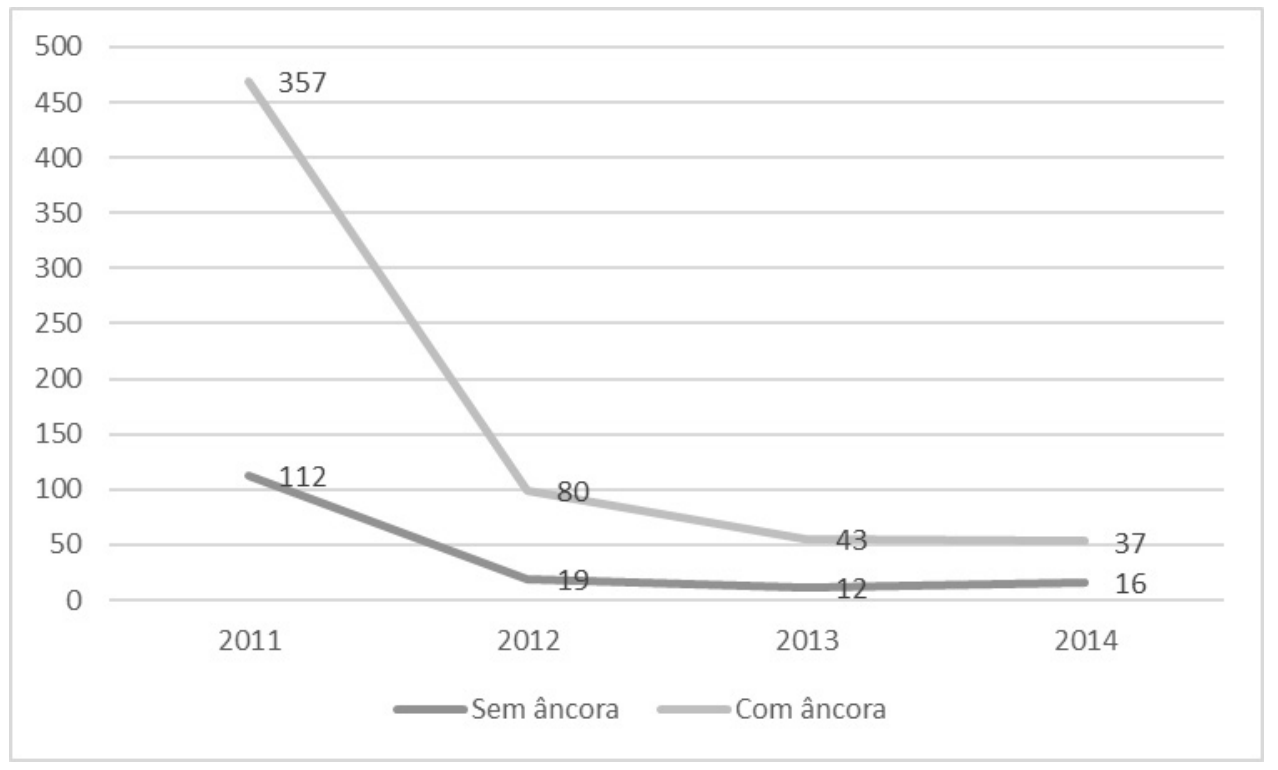

Fonte: TJRJ. Elaboração própria.

Por fim, todos os valores de pedidos de indenização por danos morais foram analisados. Foram excluídos vinte e oito casos que apresentaram inconsistências, com valores de indenização deferidos acima do que foi pedido pelas partes, sessenta e sete casos com valores deferidos computados como zero e outros sete casos, que apresentaram valores muito acima de 40 salários mínimos. Isso resultou em um universo final de 422 processos eletrônicos contendo todos os dados necessários para análise ${ }^{28}$.

\section{ANÁLISE}

Seguindo os procedimentos usados no trabalho anterior, foram realizadas análises de correlação entre os valores de indenização, dessa vez, efetivamente pedidos pelas partes e deferidos na decisão judicial. Vale ressaltar que, ainda, não foi possível identificar claramente processos envolvendo problemas idênticos, mas com variação, apenas, nos valores de pedidos de indenização por danos morais feitos pelas partes ${ }^{29}$. Esta seria uma situação ideal para o teste sobre efeitos de ancoragem em decisões judiciais, comparável ao tipo de teste feito em experimentos. O que se conseguiu fazer foi identificar grandes áreas de pedidos de indenização que podem tornar os processos um pouco mais comparáveis. As áreas definidas foram as seguintes: a) "varejo", o que inclui processos contra empresas de vendas de produtos diversos no varejo, envolvendo empresas como Casas Bahia, Ricardo Eletro, Ponto Frio etc.; b) "telecomunicações”, que se refere a processos

28 Neste estudo foram analisados todos os processos eletrônicos com informações consistentes de pedidos de danos morais dos I e II Juizados Especiais Cíveis. Nesse caso, os processos analisados se enquadram no que Moretin e Bussab chamam de "levantamentos observacionais". Diferente de levantamentos amostrais probabilísticos "que usam mecanismos aleatórios de seleção dos elementos de uma amostra, atribuindo a cada um deles uma probabilidade, conhecida a priori, de pertencer à amostra", nos levantamentos observacionais "os dados são coletados sem que o pesquisador tenha o controle sobre as informações obtidas, exceto eventualmente sobre possíveis erros grosseiros”. Cf. MORETIN, Pedro Alberto; BUSSAB, Wilton de Oliveira. Estatística básica. São Paulo: Saraiva, 2004. p. 261.

29 Isso não significa, porém, que casos semelhantes não tenham sido constatados. Um exemplo envolve os processos 1731 98.2011.8.19.0209 e 15246-06.2011.8.19.0209. Nos dois casos estava em jogo a entrega intempestiva de eletrodomésticos comprados em sites de varejo (respectivamente um ventilador de teto e um refrigerador). Nos dois casos os consumidores começaram a pagar parcelas de financiamento do produto antes de recebê-lo. No primeiro caso, o pedido de indenização por danos morais foi de $\mathrm{R} \$ 10.141,00$, enquanto no segundo o pedido foi de $\mathrm{R} \$ 5.000,00$. Após as decisões, os pedidos de indenização foram deferidos nos montantes de, respectivamente, $\mathrm{R} \$ 4.480,66$ (correspondente a 44,2\% do pedido) e $\mathrm{R} \$ 1.629,37$ (correspondente a 32,58\% do pedido). 
contra empresas de telecomunicações, como empresas de telefonia, provedores de internet etc.; "bancos", que diz respeito a processos contra bancos e financeiras; e "aéreas", formada por processos contra companhias aéreas. Como se nota, os setores foram definidos em função dos réus das ações. Sendo assim, foram feitas análises dos dados com todos os processos, em um primeiro momento e análises em cada uma dessas grandes áreas. Da mesma forma que argumentado no estudo anterior, apesar de não haver condições para um teste ideal sobre os efeitos de ancoragem nas decisões judiciais, o estudo permite observar correlações interessantes entre pedidos de danos morais feitos pelas partes e os valores de indenização por danos morais feitos pelos juízes que podem oferecer algumas pistas a respeito de situações que podem alterar os efeitos desse tipo de heurística. A grande diferença desse estudo, como anunciado, é poder contar com valores exatos de pedidos e deferimentos de danos morais, além de poder observar correlações em áreas específicas (telecomunicações, varejo, bancos, aéreas).

\subsection{Valores pedidos e valores deferidos: análise com todos os processos}

Os valores de indenização por danos morais pedidos apresentam muita variação, como pode ser visualizado no gráfico 3. Em média os pedidos giram em torno de $\mathrm{R} \$ 15.950,00$, mas com elevado desvio padrão (quase $\mathrm{R} \$ 8.786,00)$. O valor mediano é próximo da média, chegando a $\mathrm{R} \$ 13.900,00$. Poucos casos, no entanto, ultrapassam o valor máximo de 40 salários mínimos, já que 75\% dos casos são de até R $24.628,00$ — valor de 40 salários mínimos em 2015 seria de R \$31.520,00. Por outro lado, os valores de indenização deferidos são bem inferiores. A média das indenizações por danos morais concedida no período foi de cerca de $R$ \$ 4.268,00. A distribuição das indenizações deferidas revela que os valores se concentram em níveis relativamente baixos. A grande maioria dos processos (75\%) não obteve indenização acima de $\mathrm{R} \$ 5.733,00$ (gráfico 4).

Gráfico 3 - Distribução dos valores de pedidos de danos morais (dados deflacionados 2015)

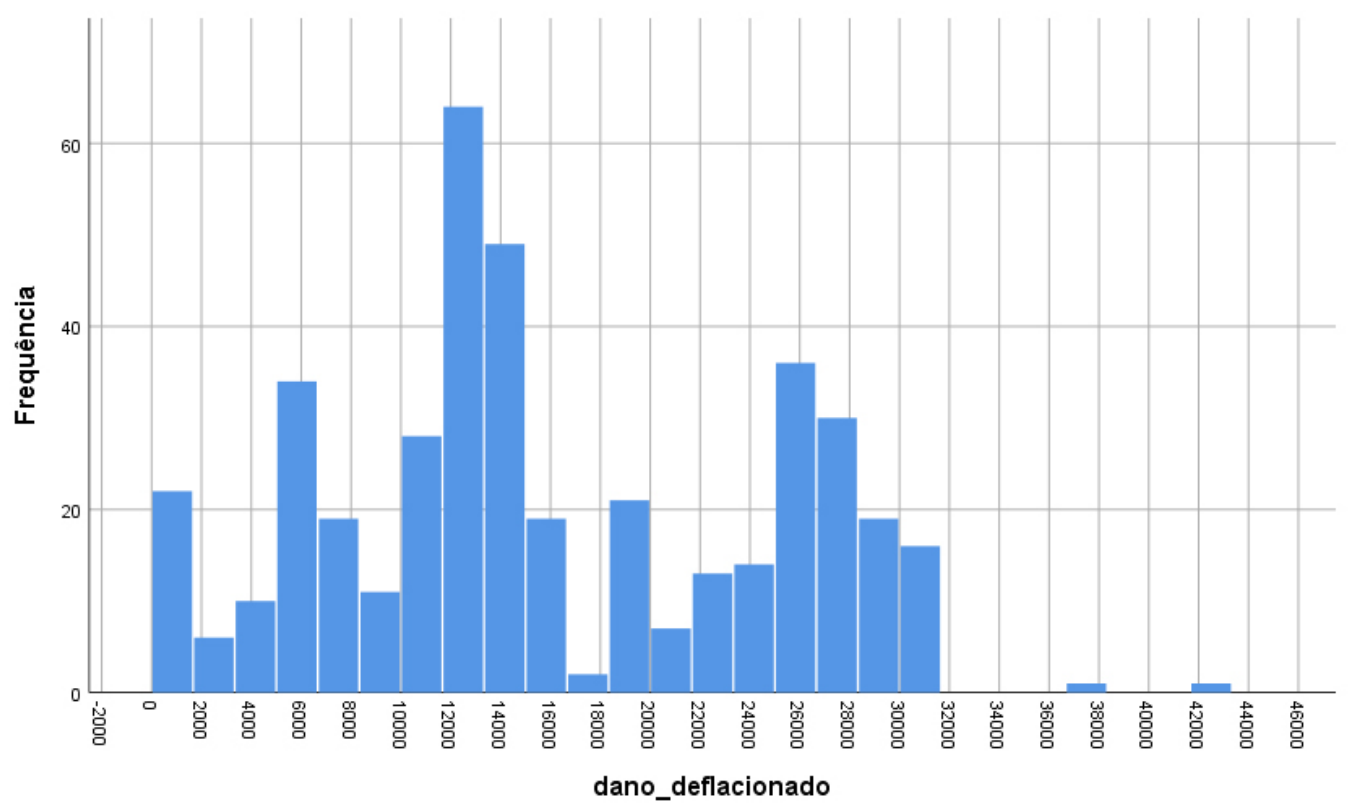

Fonte: TJRJ. Elaboração própria. 
Gráfico 4 - Distribuição dos valores de pedidos de danos morais (dados deflacionados 2015)

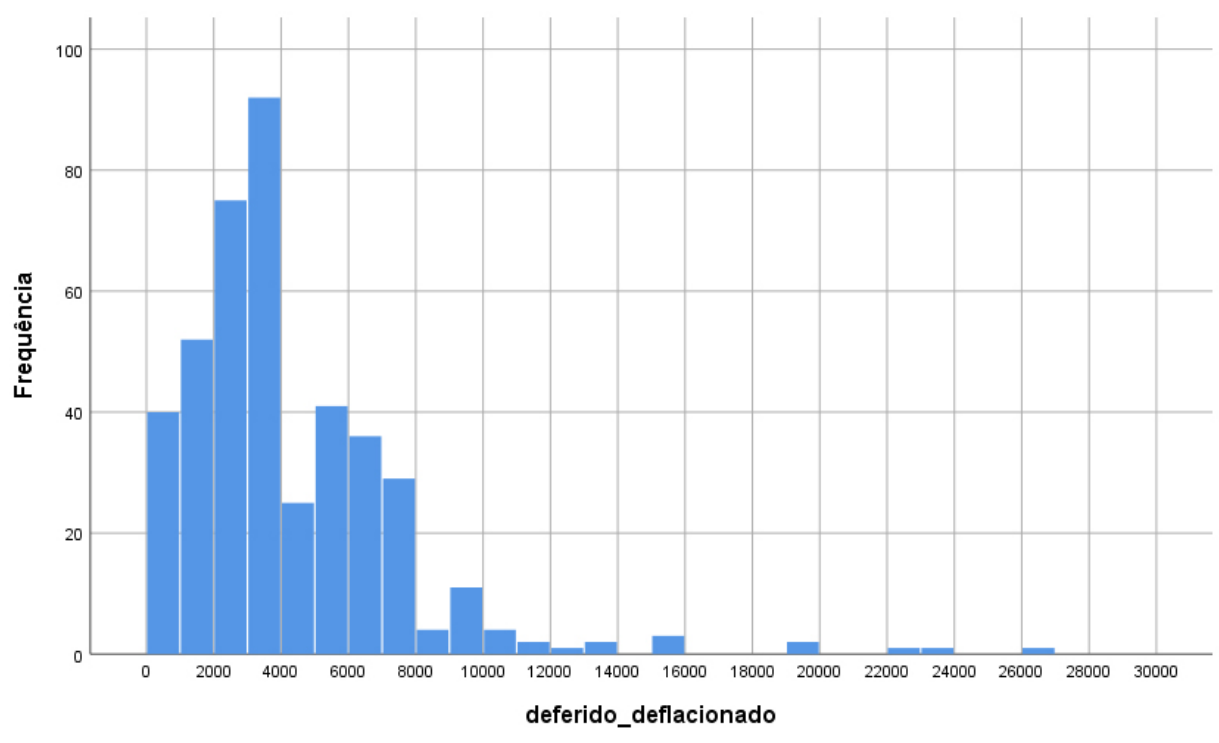

Fonte: TJRJ. Elaboração própria.

Tabela 1 - Valores pedidos e deferidos de indenização por danos morais: média, desvio padrão, mediana e percentil 75

\begin{tabular}{l|l|l}
\hline & $\begin{array}{l}\text { Valores Pedidos } \\
(\mathbf{R} \$ \mathbf{)}\end{array}$ & $\begin{array}{l}\text { Valores deferidos } \\
(\mathbf{R} \$ \mathbf{)}\end{array}$ \\
\hline Média & 15950,7 & 4268,0 \\
\hline Desvio & 8786,8 & 3346,0 \\
\hline Mediana & 13912,5 & 3860,9 \\
\hline Percentil 0,75 & 24628,9 & 5733,3 \\
\hline
\end{tabular}

Fonte: TJRJ. Elaboração própria.

A correlação entre os valores de indenização por danos morais pedidos e os valores deferidos pelos juízes revelam uma associação fraca entre ambos (gráfico 5). O Índice de Correlação de Spearman nesse caso é de $0,38^{30}$. Como pode ser observado no gráfico abaixo, a variação em torno da reta de ajuste é bastante elevada, o que indica que há muita variação nos valores deferidos para um mesmo valor pedido. Ou seja, não há uma clara tendência de aumento de valor deferido à medida que as partes aumentam os valores pedidos. A princípio, portanto, haveria poucos indícios de algum tipo de efeito de ancoragem na decisão judicial. No entanto, é importante lembrar que os dados agregam casos bastante diferentes, que vão desde pedidos de indenização feitos a companhias aéreas a casos envolvendo telecomunicações ou empresas de entregas de produtos de varejo.

30 Para mensurar o grau de associação entre os valores de danos morais pedidos e deferidos, foi utilizado a correlação de Spearman, que é um teste estatístico não paramétrico e que, portanto, não exige nenhum pressuposto de normalidade na distribuição dos dados analisados. A correlação de Spearman foi escolhida uma vez que, tanto os valores de pedidos de danos morais como os valores deferidos pelos juízes não apresentam uma distribuição normal. 
Gráfico 5 - Relação entre valor de indenização por dano moral pedido e valor deferido

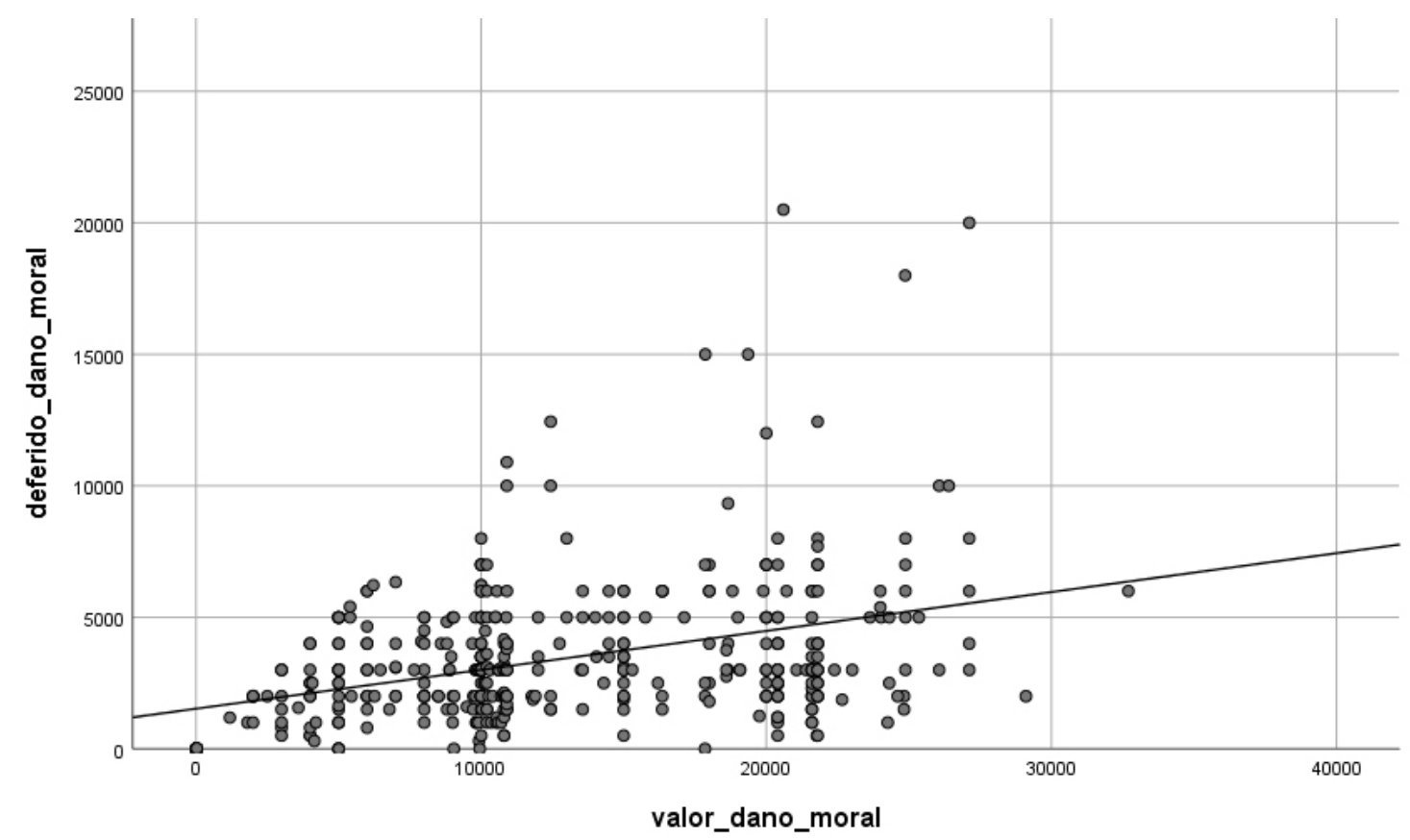

Fonte: TJRJ. Elaboração própria.

Mesmo assim, o estudo explorou hipóteses alternativas capazes de fornecer indicações do efeito de ancoragem nas decisões. Especificamente e seguindo os achados do estudo anterior, foram feitas correlações para testar se as seguintes situações poderiam alterar possíveis efeitos de ancoragem nas decisões judiciais: se pedidos de indenização com valores mais baixos (abaixo do valor mediano) ou pedidos de indenização com valores "redondos" poderiam deixar os juízes mais suscetíveis à influência da heurística de ancoragem do que processos em que os pedidos apresentam valores mais elevados ou em que os pedidos são formulados por meio de valores "quebrados". A grande diferença é que, neste estudo, foi possível realizar esses testes contando com os valores exatos dos pedidos de indenização por danos morais feitos pelas partes concedidos na decisão judicial.

Nesse sentido, foi realizada uma comparação nas correlações entre os pedidos de indenização e a quantia deferida na decisão judicial envolvendo um grupo com processos com valores abaixo de $\mathrm{R} \$ 15.000,00$ (aproximadamente o valor mediano e aproximadamente o correspondente ao valor de 20 salários mínimos) e outro com os demais casos (acima de $\mathrm{R} \$ 15.000,00)$. Os resultados das correlações nesse caso revelam diferença substantiva ente a intensidade da associação entre os valores pedidos e concedidos nas duas situações. A respeito dos pedidos feitos abaixo do valor de $\mathrm{R} \$ 15.000,00$, a correlação é de 0,36. Em relação aos processos com pedidos acima desse valor, a correlação é muito fraca, atingindo 0,06 . Essa diferença é mais acentuada que a encontrada no trabalho anterior $(0,26$, contra 0,18$)$. Ainda assim, poderíamos manter a hipótese explicativa levantada no texto anterior de acordo com a qual a aproximação do pedido de dano moral do teto estabelecido em lei acaba por neutralizar a influência da heurística de ancoragem, o que pode derivar tanto da experiência acumulada dos magistrados como de eventual papel dissuasivo da regra jurídica dos vieses que podem ser produzidos pela influência de fatores intuitivos no julgamento. 
Gráfico 6 - Relação entre valores pedidos e valores deferidos abaixo de $\mathrm{R} \$ 15 \mathrm{mil}(\mathrm{N}=244)$

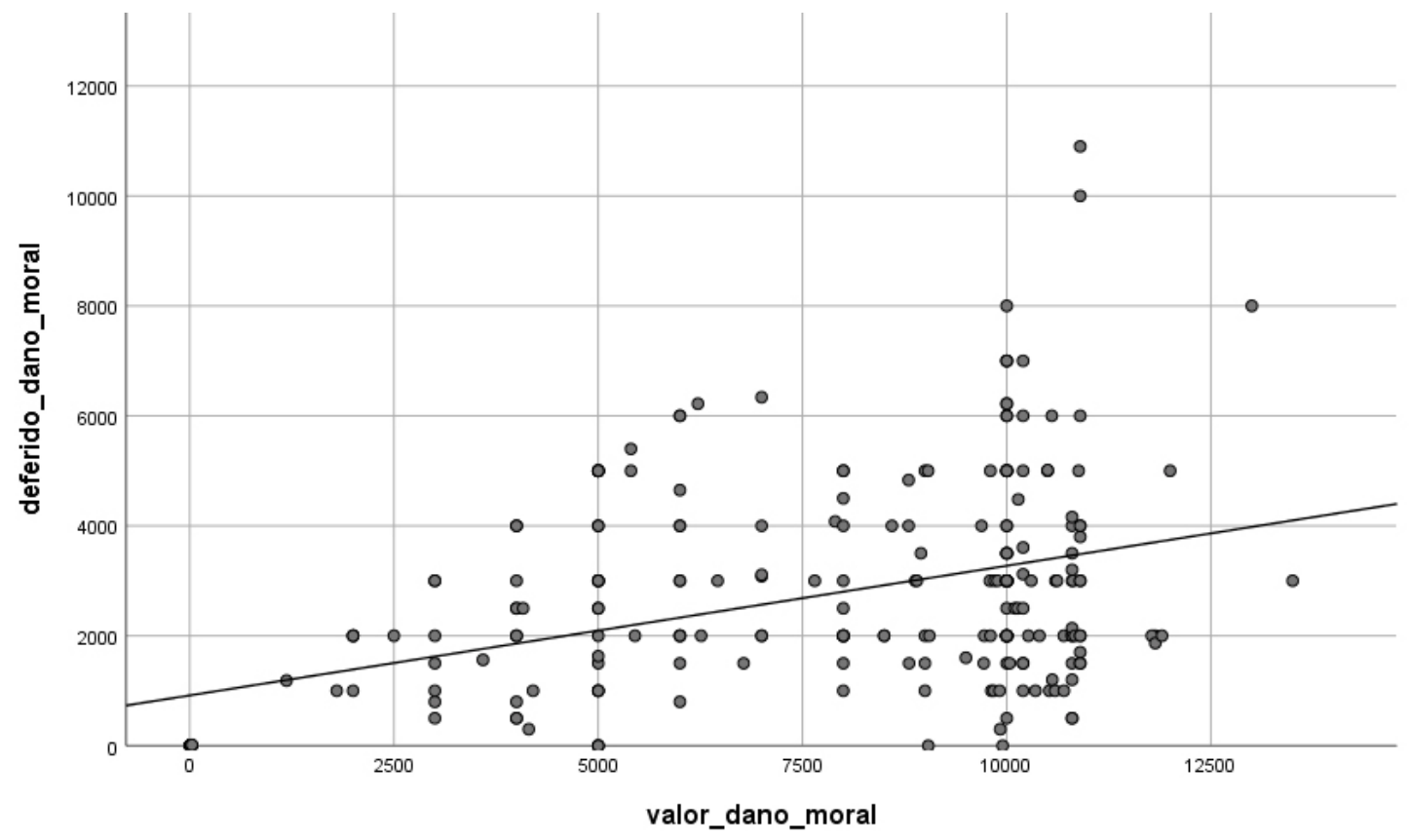

Fonte: TJRJ. Elaboração própria.

Gráfico 7 - Relação entre valores pedidos e valores deferidos acima de R $\$ 15$ mil (N 121)

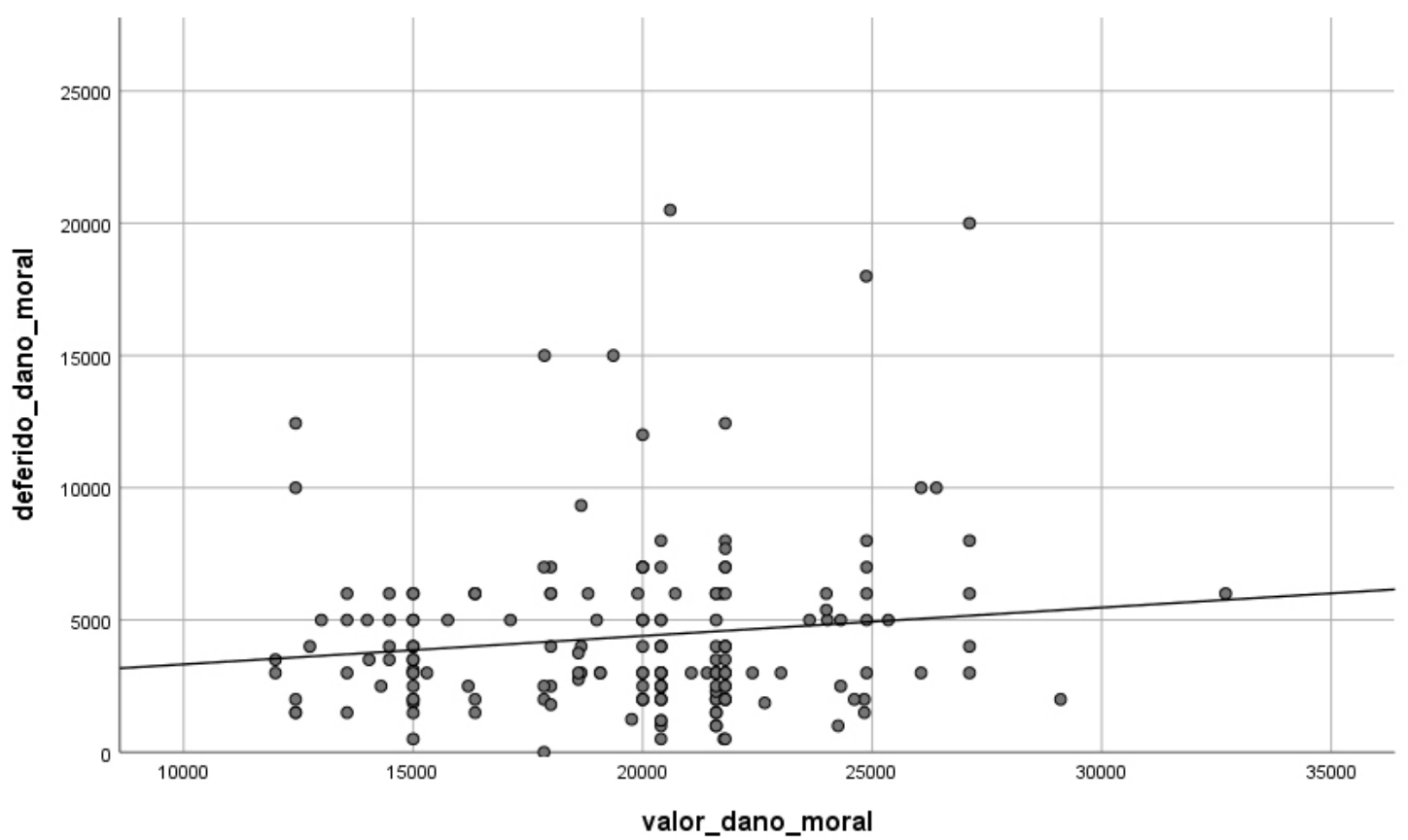

Fonte: TJRJ. Elaboração própria.

A outra hipótese testada refere-se à possibilidade de diferença no efeito de ancoragem nos casos em que os pedidos de indenização por danos morais apresentam valores "redondos" e aqueles em que os pedidos tem valores "quebrados". Da mesma forma que o teste feito acima, esses dois grupos foram separados e a correlação entre os valores pedidos e os valores deferidos foi calculada em cada caso. A correlação observada entre valores pedidos e deferidos para o grupo de pedidos com valores "redondos" é de 0,27, bem menor que o de 0,59 observado no grupo com pedidos com valores "quebrados". Embora a diferença entre essas correlações não seja elevada, esse resultado segue na mesma direção do estudo anterior e sugere que os 
pedidos baseados em valores quebrados levariam a um maior esforço de quantificação dos danos morais por parte dos juízes do que os valores redondos. Ou seja, assim como no estudo anterior, as análises comparativas acima parecem indicar que o contexto da tomada de decisão afeta os efeitos da heurística de ancoragem em decisões judiciais - no caso valores elevados e quebrados levariam a um maior esforço de quantificação da indenização feita pelos juízes.

Gráfico 8 - Relação entre valores pedidos e valores deferidos para valores redondos $\mathrm{N}=300$

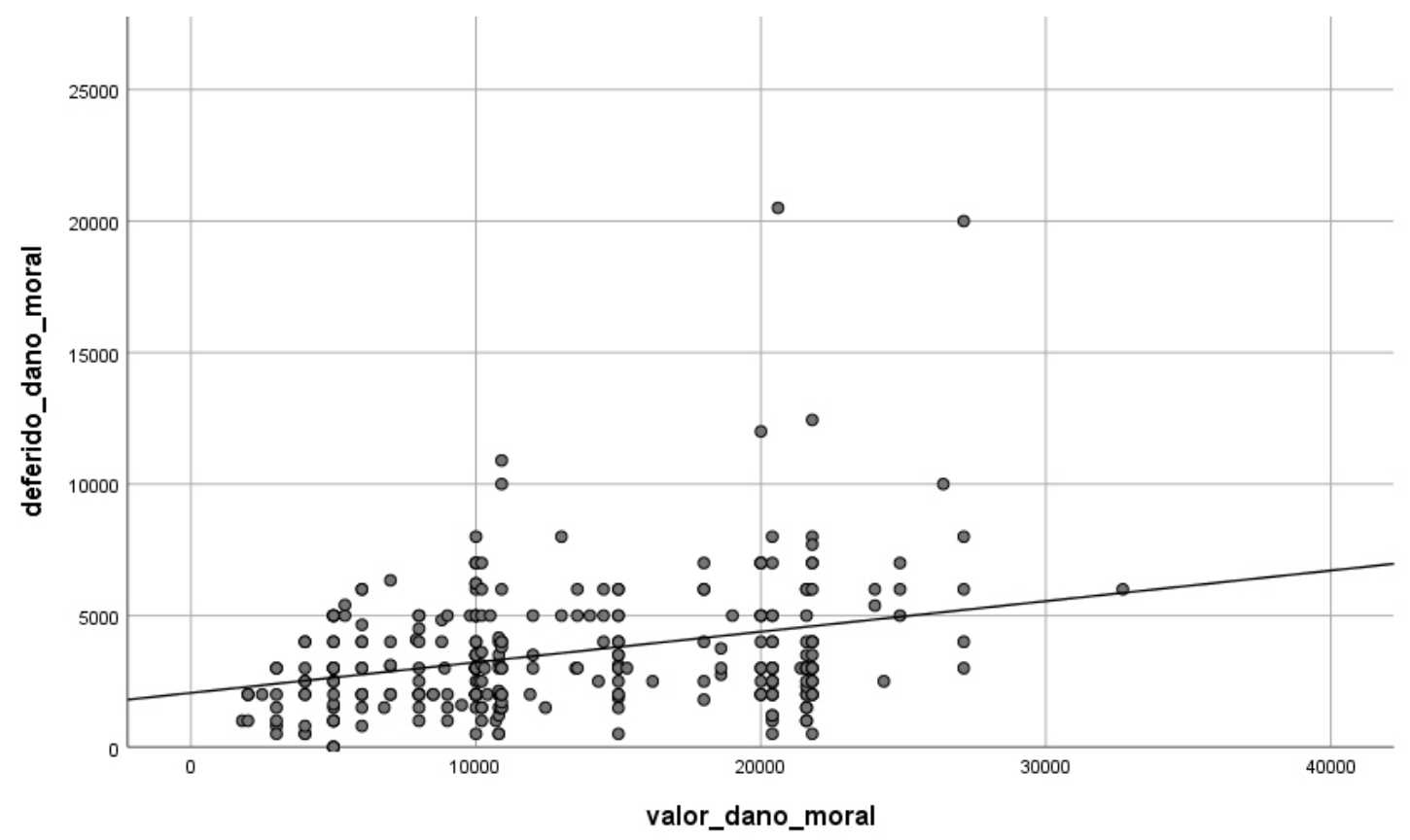

Fonte: TJRJ. Elaboração própria.

Gráfico 9 - Relação entre valores pedidos e valores deferidos para valores quebrados $\mathrm{N}=137$

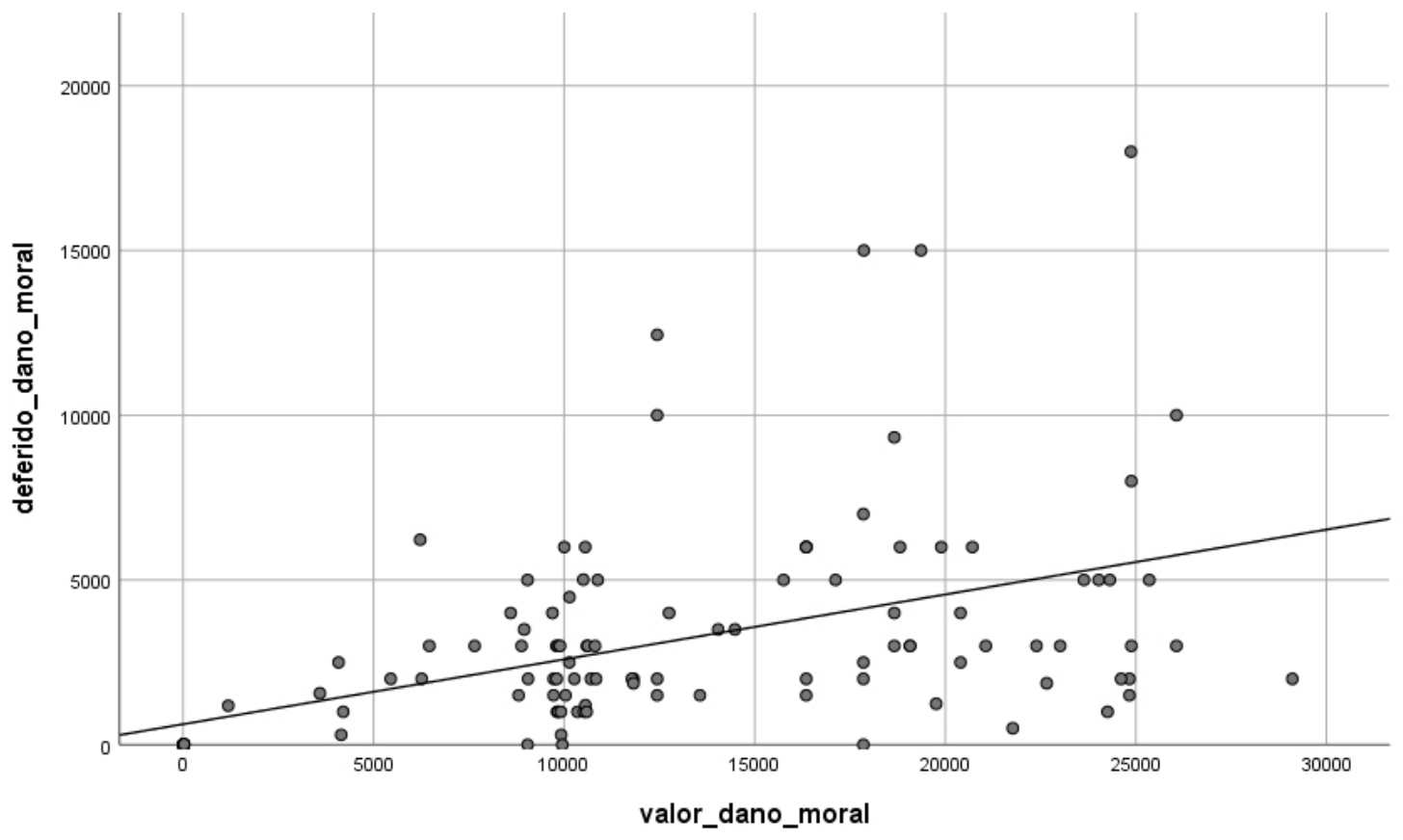

Fonte: TJRJ. Elaboração própria. 
3.2. Valores pedidos e valores deferidos: análise das áreas de telecomunicações, varejo, bancos e setor aéreo

Por fim, foram realizados testes de correlação em cada uma das áreas definidas acima: telecomunicações, varejo, bancos e aéreas. Os casos foram agrupados nesses grupos em razão dos réus. Em relação ao primeiro estudo, a base de dados permitiu estudos mais focados em razão do tema envolvido, o que possibilitou explorar eventuais variações do efeito de ancoragem. A partir dessa categorização, os valores médios de indenização por danos morais feitos nas áreas de telecomunicações e bancos são superiores aos valores pedidos nas demais áreas - e, também superior ao valor médio considerando-se todos os casos analisados (tabela 1). Assim como ocorre em todos os casos, há uma grande diferença entre os valores pedidos e os valores deferidos na decisão judicial. Em síntese, pode-se observar que os valores pedidos em questões que envolvem o setor bancário são os maiores, enquanto os valores deferidos no setor aéreo são os mais elevados. Vale ressaltar que, na média, os valores deferidos no caso das aéreas chega a ser quase o dobro do valor deferido nas áreas varejo e telecomunicações.

Tabela 2 - Valores pedidos e deferidos de indenização por danos morais nas áreas de telecomunicações, varejo, bancos e aéreas: média, desvio padrão, mediana e percentil 75

\begin{tabular}{|c|c|c|c|c|c|c|c|c|}
\hline & \multicolumn{2}{|c|}{ Telecomunicações } & \multicolumn{2}{|c|}{ Varejo } & \multicolumn{2}{|c|}{ Bancos } & \multicolumn{2}{|c|}{ Setor aéreo } \\
\hline & $\begin{array}{c}\text { Valor } \\
\text { pedido } \\
(\mathrm{R} \$)\end{array}$ & $\begin{array}{c}\text { Valor } \\
\text { deferido } \\
(\mathrm{R} \$)\end{array}$ & $\begin{array}{c}\text { Valor } \\
\text { pedido } \\
(\mathbf{R} \$)\end{array}$ & $\begin{array}{c}\text { Valor } \\
\text { deferido } \\
(\mathrm{R} \$)\end{array}$ & $\begin{array}{c}\text { Valor } \\
\text { pedido } \\
(\mathrm{R} \$)\end{array}$ & $\begin{array}{c}\text { Valor } \\
\text { deferido } \\
(\mathrm{R} \$)\end{array}$ & $\begin{array}{c}\text { Valor } \\
\text { pedido } \\
(\mathrm{R} \$)\end{array}$ & $\begin{array}{c}\text { Valor } \\
\text { deferido } \\
(\mathrm{R} \$)\end{array}$ \\
\hline Média & 18287,9 & 3725,1 & 14438,3 & 3468,6 & 19135,3 & 4878,5 & 15756,1 & 6717,7 \\
\hline Desvio & 9077,1 & 2166,7 & 8811,2 & 2313,1 & 8184,4 & 4390,2 & 8082,9 & 5358,5 \\
\hline Mediana & 13003,6 & 3901,1 & 13003,6 & 2600,7 & 19505,4 & 3901.0 & 14066,6 & 5650,0 \\
\hline Percentil 75 & 26527,3 & 4057,3 & 21260,9 & 4885,9 & 26783,2 & 5350,1 & 23211,4 & 7802,1 \\
\hline Spearman & \multicolumn{2}{|c|}{0,29} & \multicolumn{2}{|c|}{0,38} & \multicolumn{2}{|c|}{0,25} & \multicolumn{2}{|c|}{0,52} \\
\hline $\mathbf{N}$ & \multicolumn{2}{|c|}{73} & \multicolumn{2}{|c|}{182} & \multicolumn{2}{|c|}{50} & \multicolumn{2}{|c|}{54} \\
\hline
\end{tabular}

Fonte: TJRJ. Elaboração própria.

As correlações entre os valores de indenização pedidos e deferidos segue o mesmo padrão dos valores encontrados na análise com todos os casos, em torno de 0,30 , exceto no setor "aéreas". De fato, a correlação encontrada nesse setor regulado difere muito das demais, atingindo um índice de 0,52 - a correlação mais forte observada em todo o estudo. As correlações entre os valores de danos morais pedidos e concedidos dessas quatro grandes áreas podem ser observadas nos gráficos abaixo. O gráfico 10 apresenta a correlação calculada para os pedidos de danos morais da área telecomunicações. Observa-se dois grandes agrupamentos de pedidos, um em torno de $\mathrm{R} \$ 10.000,00$ e outro em torno de $\mathrm{R} \$ 20.000,00$ a $\mathrm{R} \$ 25.000,00$. Em ambos os caos há uma grande variação de valores de danos morais deferidos. $\mathrm{Na}$ linha de pedidos na casa dos 25 mil reais, por exemplo, os valores deferidos vão de cerca de 2 mil reais a 12 mil reais. Seria preciso saber se há grandes diferenças nos problemas relacionados aos pedidos nesse setor para entender os motivos dessa variação. No entanto, embora a correlação seja baixa e a variação seja razoavelmente alta, os valores mais altos homologados nas decisões judiciais se encontram justamente nos pedidos de danos morais mais elevados. No primeiro agrupamento, por exemplo, os valores deferidos de danos morais não chegam a 8 mil reais. Uma das possíveis explicações para essa aparente homogeneização pode ser o tabelamento dos valores deferidos pelos juízos. Para explorar essa hipótese explicativa, buscamos a ocorrência de valores que se repetem com alguma frequência.

No universo total de casos, os valores exatos de $\mathrm{R} \$ 2.000,00$ e $\mathrm{R} \$ 3.000,00$ são os mais recorrentes, correspondendo, respectivamente, a 14,9\% e 15,2\% do total - sendo que os valores exatos de $\mathrm{R} \$ 1.000,00$ (5\%), $\mathrm{R} \$ 2.000,00(14,9 \%), \mathrm{R} \$ 3.000,00(15,2 \%), \mathrm{R} \$ 4.000,00$ e $\mathrm{R} \$ 5.000,00$ (7,3\%) somam um pouco mais de me- 
tade das indenizações por danos morais (51,9\%). Esse padrão de valores frequentes de indenização se repete nos setores de telecomunicações - no qual o valor de indenização de $\mathrm{R} \$ 2.000,00$ corresponde a 15,1\% e o de $\mathrm{R} \$ 3.000,00$ soma $23,3 \%$ dos processos - e varejo - com o valor de indenização de $\mathrm{R} \$ 2.000,00$ atingindo $17 \%$ dos casos e o de $\mathrm{R} \$ 3.000,0013,2 \%$. No setor aéreas, os valores de indenização mais recorrentes são de $\mathrm{R} \$ 3.000,00$ (20,4\%) e $\mathrm{R} \$ 6.000,00$ (18,4\%). Já no setor bancos as indenizações mais frequentes são, as de $\mathrm{R} \$ 2.000,00, \mathrm{R} \$ 3.000,00$ e $\mathrm{R} \$ 4.000,00$, todas elas igualmente atingindo 16\% do total de processos. Embora não se possa inferir a existência de tabelamento a partir dos dados levantados, é curioso notar a concentração de valores deferidos em uma faixa que varia de $\mathrm{R} \$ 1.000,00$ a $\mathrm{R} \$ 5.000,00$. Além disso, a frequência com que os mesmos valores aparecem nos Juizados analisados podem sugerir que casos diferentes recebem o mesmo tratamento.

Gráfico 10 - Relação entre valor de indenização por dano moral pedido e valor deferido: Telecomunicações

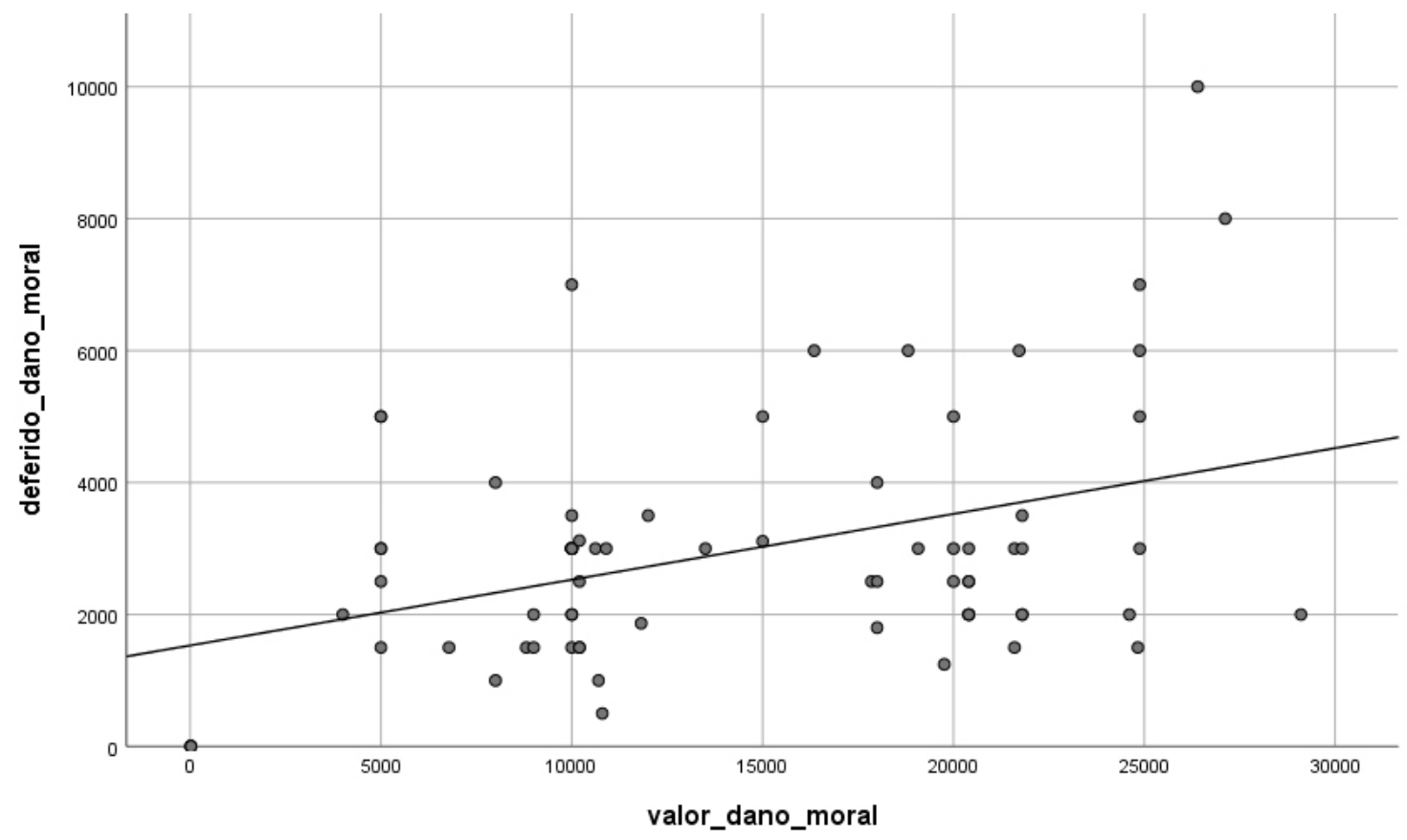

Fonte: TJRJ. Elaboração própria.

As correlações encontradas no setor de varejo e nos bancos apresentam uma distribuição um pouco diferente. Há uma grande dispersão de valores deferidos em todas as faixas de pedidos de indenização por danos morais, atingindo em sua maioria até 8 mil reais no primeiro caso e até 7 mil reais no segundo (gráficos 11 e 12). A diferença é que no setor bancos há um caso discrepante em que um alto valor de indenização foi pedido e concedido (o valor pedido, atualizado para valores de 2015 , foi de $R \$ 26.787,87$ e o valor deferido foi de $\mathrm{R} \$ 26.657,34)$. 
Gráfico 11 - Relação entre valor de indenização por dano moral pedido e valor deferido: Varejo

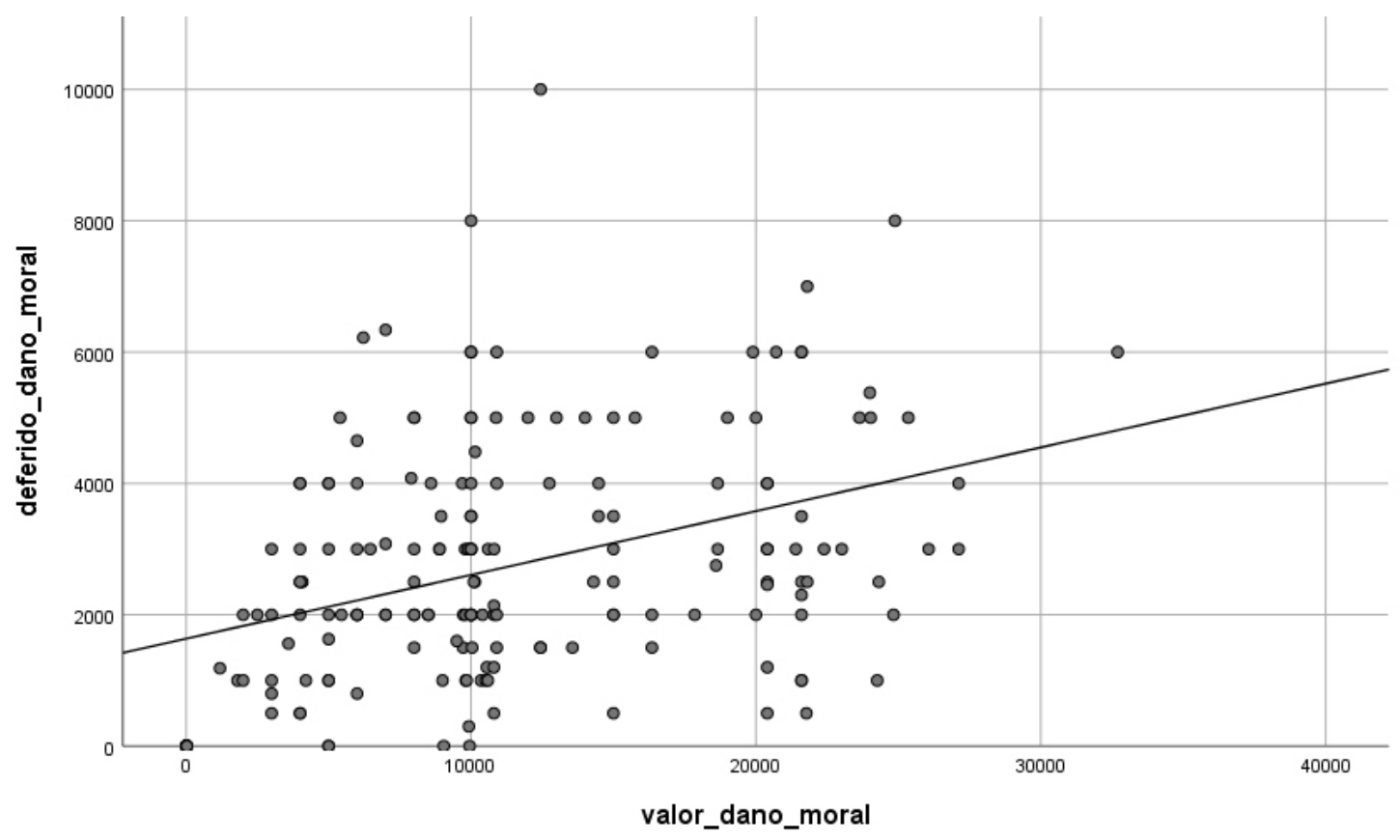

Fonte: TJRJ. Elaboração própria.

Gráfico 12 - Relação entre valor de indenização por dano moral pedido e valor deferido: Bancos

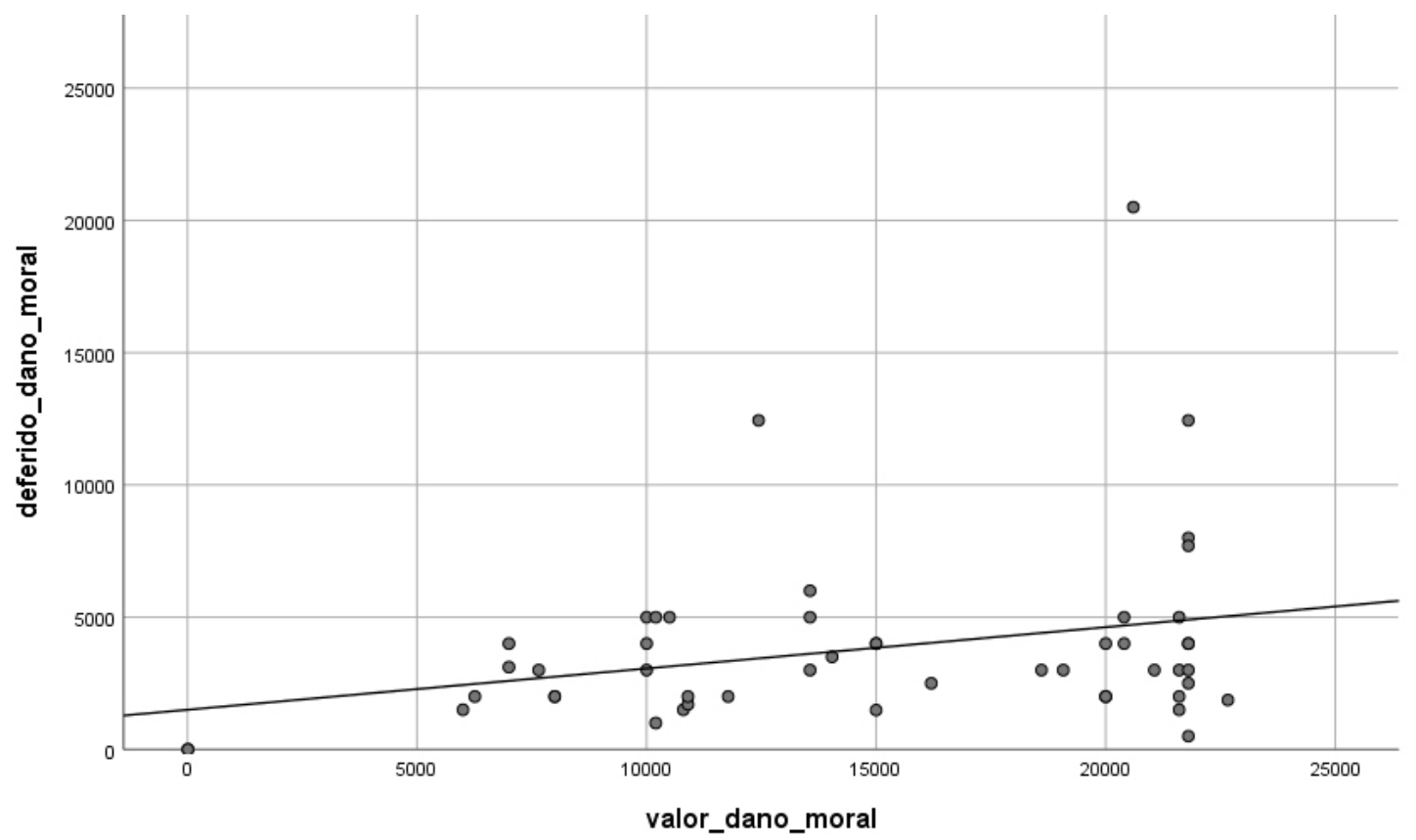

Fonte: TJRJ. Elaboração própria.

Por fim, o gráfico 13 apresenta a correlação calculada para o setor aéreas. Observa-se nitidamente a correlação média entre o valor de dano moral pedido e concedido nesse caso. A questão seria saber o que diferenciaria esse setor dos demais casos em que as correlações encontradas são mais baixas e mais semelhantes a encontrada quando todos os dados são levados em consideração. 
Gráfico 13 - Relação entre valor de indenização por dano moral pedido e valor deferido: Aéreas

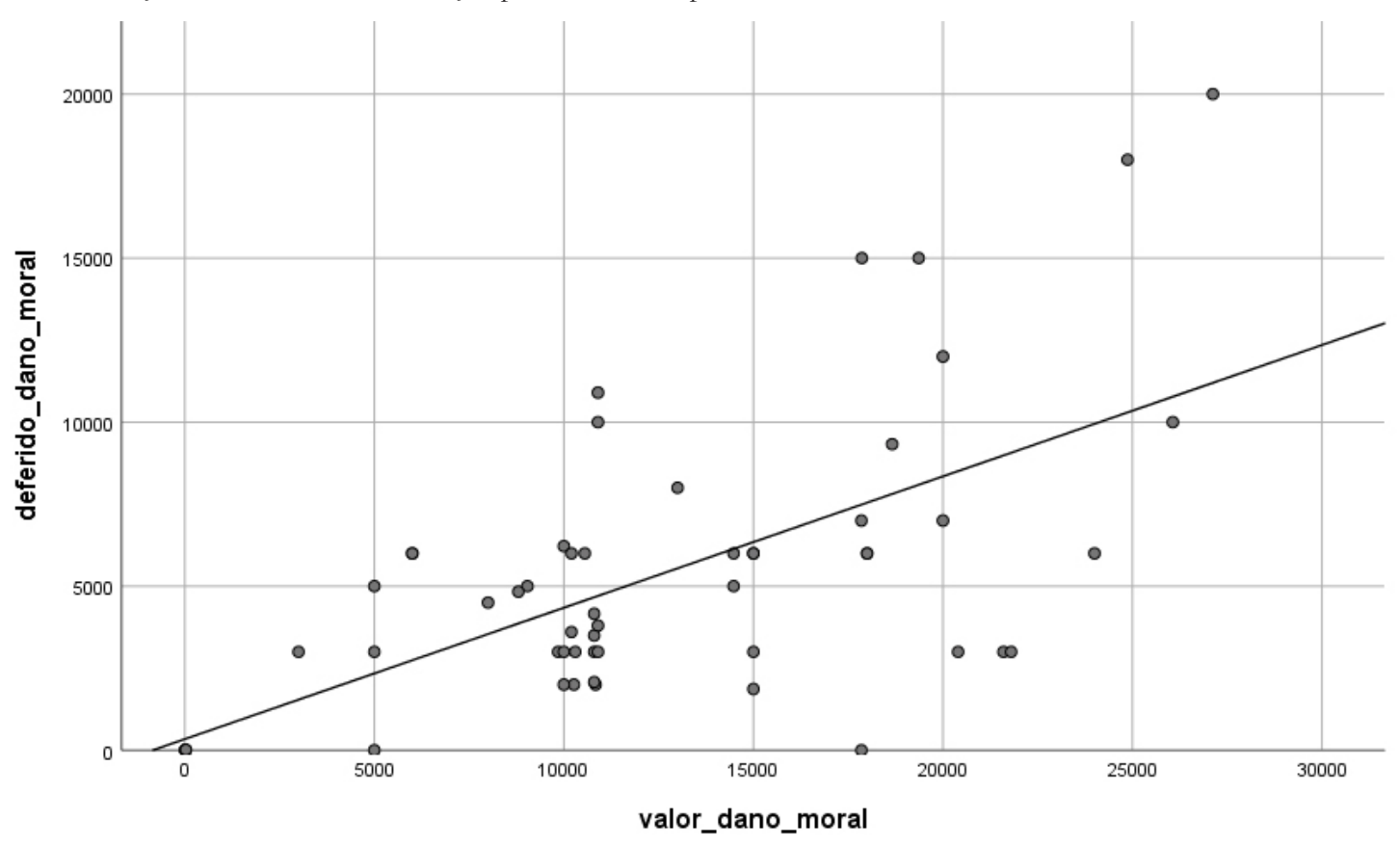

Fonte: TJRJ. Elaboração própria.

\section{Considerações finais}

O presente trabalho buscou investigar a influência de fatores intuitivos na tomada de decisão judicial. Mais especificamente, testes de correlação foram feitos visando à identificação de efeitos de ancoragem na apreciação de pedidos de danos morais em Juizados Especiais da Barra da Tijuca, no Rio de Janeiro. Ao contrário do que foi feito em estudo anterior, desta vez foi possível reunir informações suficientes para apreciar as correlações entre o valor efetivamente pedido pelas partes (e não o valor da causa) e o valor de danos morais deferido ao final. Além disso, foi possível, em razão dos réus, agrupar os casos analisados em quatro setores específicos (varejo, telecomunicações, bancário e aéreo), o que permitiu explorar correlações em diferentes universos. Partiu-se da hipótese de que os valores sugeridos pelas partes funcionariam como âncoras a partir das quais os juízes fixariam os valores, ainda que pudessem variar por setores. Assim, casos semelhantes poderiam ter tratamento diferente apenas em razão dos valores pedidos pelas partes em cada caso.

As análises foram feitas com um conjunto de 524 processos tomando como referência o valor pedido efetivamente pelos autores, e não o valor da causa. As análises de correlação, no geral, confirmaram as conclusões encontradas quando apenas o valor da causa foi usado como possível âncora. Isso significa, em primeiro lugar, que, assim como na análise anterior, valores pedidos mais altos tendem a manter uma associação mais fraca com os valores deferidos. Ao contrário disso, em segundo lugar, quanto mais baixo o valor pedido, maior é a correlação que se pode estabelecer entre a referência indicada pelo autor e o valor deferido judicialmente. Ademais, em terceiro lugar, valores "quebrados" tendem a estar mais fortemente correlacionados aos montantes deferidos, ao contrário do que ocorre com valores "redondos". Em todos os casos, no entanto, as correlações não foram fortes o suficiente para justificarem a constatação de influência da heurística de ajuste e ancoragem nos julgamentos, o que permite afirmar que a hipótese da qual se partiu não foi confirmada. Finalmente, a presente análise confirmou a plausibilidade da análise anterior, que assumiu não ser necessariamente um problema na análise de possível influência de heurística de ancoragem 
em decisões de Juizados Especiais Cíveis explorar as correlações tendo como referência o valor atribuído à causa. Isso porque, em razão de características típicas dos processos (como a possibilidade de a ação ser proposta sem assistência advocatícia, a regra de acesso sem a necessidade de pagamento de custas e não haver, salvo na hipótese de recurso, sucumbência ${ }^{31}$ ), tenderia a haver identidade entre o valor da causa e o valor pedido pelas partes, notadamente nos casos em que o pedido de dano moral não fosse cumulado com pedido de dano material.

As informações contidas na nova base dados explorada neste trabalho permitiram, ainda, testes de correlação entre valores pedidos e deferidos em razão do tema envolvido nos casos. Tomando por base os diferentes réus em face dos quais foram propostas as ações apreciadas, os processos foram agrupados em quatro grandes setores: telecomunicações, varejo, transporte aéreo e bancário. Em cada um dos setores, as correlações gerais se mantiveram, exceto nas questões envolvendo o setor aéreo. Nesse terreno, o índice de correlação de Spearman atinge 0,57 , o que sugere uma influência mais forte da heurística de ancoragem na tomada de decisão judicial. Esse é, sem dúvida, um dado que merece a especial atenção em estudos posteriores.

A não constatação de influência da heurística de ancoragem, ressalvado os casos envolvendo o setor aéreo, não pode, contudo, ser considerado de todo irrelevante. Se, por um lado, parece haver pouco espaço para a afetação de processos decisórios reais por fatores intuitivos, por outro não se pode dizer que a prática judicial relacionada à fixação de danos morais possa ser considerada funcional. Tabelamentos de danos morais e outras inclinações do comportamento judicial que evitam a particularização dos casos podem revelar problemas jurídicos que estão para além da influência de vieses na tomada de decisão. A não confirmação da hipótese de que se partiu e a sugestão de que outras disfuncionalidades podem afetar a decisão judicial seguem como conclusões importantes para inspirar o desenvolvimento de futuras pesquisas destinadas à compreensão empiricamente informada de processos reais de tomada de decisão jurídica e a busca por soluções adequadas para os diagnósticos formulados.

\section{REFERÊNCIAS}

ALEXY, Robert. Principais elementos de uma teoria da dupla natureza do direito. Revista de Direito Administrativo, n. 253, p. 9-29, 2010.

ARGUELHES, Diego Werneck; LEAL, Fernando. O argumento das “capacidades institucionais" entre a banalidade, a redundância e o absurdo. Direito, Estado e Sociedade, n. 38, p. 6-50, jan./jun. 2011.

BARROSO, Luís Roberto. A doutrina brasileira da efetividade. In: BARROSO, Luís Roberto. (Org.). O direito constitucional e a efetividade de suas normas: limites e possibilidades da Constituição brasileira. 8. ed. Rio de Janeiro: Renovar, 2006.

ENGLICH, Birte; MUSSWEILER, Thomas; STRACK, Fritz. Playing dice with criminal sentences: the influence of irrelevant anchors on expert's judicial decision-making. Personality and Social Psychology Bulletin, v. 32, n. 2, p. 188-200, fev. 2006.

ESTADOS UNIDOS DA AMÉRICA. Library of Congress. General information. Disponível em: < https:// www.loc.gov/about/general-information/\#year-at-a-glance>. Acesso em: 22 maio 2018.

FARIÑA, Francisca; ARCE, Ramón; NOVO, Mercedes. Anchoring in judicial decision-making. Psychology in Spain, v. 7, n. 1, p. 56-65, 2003.

31 LEAL, Fernando; RIBEIRO, Leandro Molhano. O direito é sempre relevante? Heurística de ancoragem e fixação de valores indenizatórios em pedidos de dano moral em juizados especiais do Rio de Janeiro. Direitos Fundamentais e Justiça, Belo Horizonte, a. 10 , n. 35, p. 253-284, jul./ dez. 2016. p. 268, nota 22. 
GUTHRIE, Chris; RACHLINSKI, Jeffrey; WISTRICH, Andrew. Blinking on the bench: how judges decide cases. Cornell Law Faculty Publications, v. 93, paper 917, p. 1-43, 2007.

KAHNEMAN, Daniel. Maps of bounded rationality: psychology for behavioral economics. The American Economic Review, v. 93, n. 5, p. 1449-1475, dez. 2003.

KAHNEMAN, Daniel. Rápido e devagar: duas formas de pensar. Objetiva: Rio de Janeiro, 2012.

KAHNEMAN, Daniel; SLOVIC, Paul; TVERSKY, Amos. Judgment under uncertainty: heuristics and biases. New York: Cambridge University Press, 1982.

LEAL, Fernando; RIBEIRO, Leandro Molhano. O direito é sempre relevante? Heurística de ancoragem e fixação de valores indenizatórios em pedidos de dano moral em juizados especiais do Rio de Janeiro. Direitos Fundamentais e Justiça, Belo Horizonte, a. 10, n. 35, p. 253-284, jul./dez. 2016.

MORETIN, Pedro Alberto; BUSSAB, Wilton de Oliveira. Estatística básica. São Paulo: Saraiva, 2004.

SIMON, Herbert A. A behavioral model of rational choice. The Quarterly Journal of Economics, v. 69, n. 1, p. 99-118, fev. 1955.

SIMON, Herbert A. Theories of decision-making in economics and behavioral science. The American Economic Review, v. 49, n. 3, p. 253-283, jun. 1959.

SOUZA NETO, Cláudio Pereira de. Fundamentação e normatividade dos direitos fundamentais: uma reconstrução teórica à luz do princípio democrático. In: BARROSO, Luís Roberto (Org). A nova interpretação constitucional: ponderação, direitos fundamentais e relações privadas. Rio de Janeiro: Renovar, 2006.

VERMEULE, Adrian. Three strategies of interpretation. San Diego Law Review, v. 42, p. 607-628, 2005. 
Para publicar na revista Brasileira de Políticas Públicas, acesse o endereço eletrônico www.rbpp.uniceub.br

Observe as normas de publicação, para facilitar e agilizar o trabalho de edição. 